EFFECTS OF MICROSTRUCTURE ON THE ELASTIC PROPERTIES OF SELECTED $\mathrm{Ta}_{2} \mathrm{O}_{5}-\mathrm{Eu}_{2} \mathrm{O}_{3}$ COMPOSITIONS

Christopher John Malarkey

M.S. Thesis Submitted To Iowa State University

Ames Laboratory, ERDA

Iowa State University

Ames, Iowa 50011

Date Transmitted: June 1977
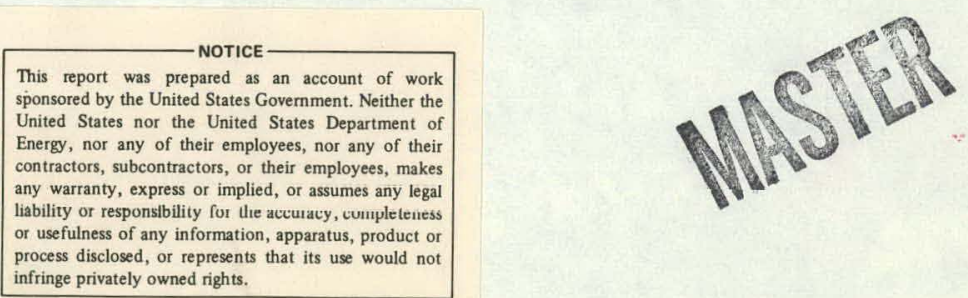

PREPARED FOR THE U.S. ENERGY RESEARCH AND DEVELOPMENT ADMINISTRATION UNDER CONTRACT NO. W-7405-eng-82 


\section{DISCLAIMER}

This report was prepared as an account of work sponsored by an agency of the United States Government. Neither the United States Government nor any agency Thereof, nor any of their employees, makes any warranty, express or implied, or assumes any legal liability or responsibility for the accuracy, completeness, or usefulness of any information, apparatus, product, or process disclosed, or represents that its use would not infringe privately owned rights. Reference herein to any specific commercial product, process, or service by trade name, trademark, manufacturer, or otherwise does not necessarily constitute or imply its endorsement, recommendation, or favoring by the United States Government or any agency thereof. The views and opinions of authors expressed herein do not necessarily state or reflect those of the United States Government or any agency thereof. 


\section{DISCLAIMER}

Portions of this document may be illegible in electronic image products. Images are produced from the best available original document. 
This report was prepared as an account of work sponsored by the United States Government. Neither the United States nor the United States Energy Research and Development Administration, nor any of their employees, nor any of their contractors, subcontractors, or their employees, makes any warranty, express or implied, or as sumes any legal liability or responsibility for the accuracy, completeness, or usefulness of any information, apparatus, product or process disclosed, or represents that its use would not infringe privately owned rights.

Available from: National Technical Information Service U. S. Department of. Commerce P.O. Box 1553 Springfield, VA 22161

Price: Microfiche $\$ 3.00$ 


\title{
Effects of microstructure on the elastic properties of selected $\mathrm{Ta}_{2} \mathrm{O}_{5}-\mathrm{Eu}_{2} \mathrm{O}_{3}$ compositions
}

by:

Christopher John Malarkey

\author{
A Thesis Submitted to the \\ Graduate Faculty in Partial Fulfillment of \\ The Requirements for the Degree of \\ MASTER OF SCIENCE
}

Department: Materials Science and Engineering

Major: Ceramic Engineering

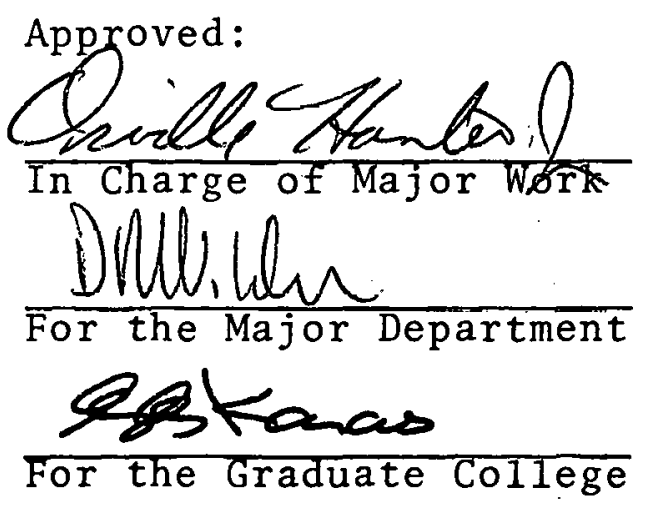

Iowa State University

Ames, Iowa 
TABLE OF CONTENTS

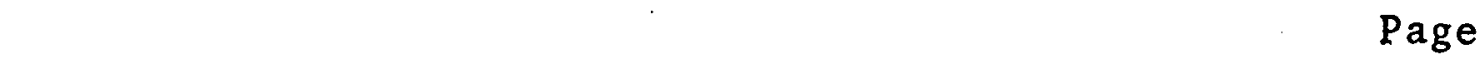

ABSTRACT

INTRODUCT ION 1

LITERATURE SURVEY 3

EXPERIMENTAL PROCEDURE 10

Specimen Fabrication 10

Elasticity Measurements 11

Internal Friction Measurements. 14

$\mathrm{X}$-ray Diffraction Measurements 17

Microstructural Analysis 18

$\begin{array}{ll}\text { RESULTS AND DISCUSSION } & 19\end{array}$

Microstructural Effects on Elastic Modulus 19 Porosity 19

Grain size 21

Microstructural Effects on Internal Friction 43

Porosity 43

Composition $\quad 44$

Average grain size 44

Sample integrity $\quad 46$

High Temperature Internal Friction 48

Thermal Expansion Anisotropies of $\mathrm{Eu}_{2} \mathrm{O}_{3}$

CONCLUSIONS 58

LITERATURE CITED $\quad 59$

ACKNOWLEDGEMENTS $\quad 64$ 


\section{ABSTRACT}

Elastic properties and internal friction of selected compositions of tantalandoped monoclinic europia were studied at temperatures up to $1500^{\circ} \mathrm{C}$ using the sonic resonance technique. Unit cell parameters between $25^{\circ} \mathrm{C}$ and $1000^{\circ} \mathrm{C}$ for monoclinic $\mathrm{Eu}_{2} \mathrm{O}_{3}$ were calculated from high temperature $\mathrm{x}$-ray diffractometer data.

Large-grained monoclinic specimens having less than 6.0 Ta cation : substitution exhibited anomalous elastic behavior when thermally cycled. Compositions above this addition level exhibited linear elastic behavior. Internal friction values also varied abnormally with grain size, composition, and temperature. The anomalous behavior was attributed to microcracking caused by thermal expansion anisotropies. The critical grain size was found to be approximately $14 \mu \mathrm{m}$.

The high temperature diffractometry measurements supported the postulate that the grain coarsening effect associated with sintered monoclinic $\mathrm{Eu}_{2} \mathrm{O}_{3}$ is the controlling factor for microcracking.

*U.S. ERDA Report IS-T-762. This work was performed under contract W-7405-eng-82 with the U.S. Energy and Research Development Administration. 


\section{INTRODUCTION}

Monoclinic europia $\left(\mathrm{Eu}_{2} \mathrm{O}_{3}\right)$ was originally dispersed in stainless steel and used as a control material in military nuclear reactors (1); however, it has become an important candidate material for two advanced reactors, the liquid metal fast breeder (LMFBR) and the gas-cooled fast reactor (GCFR) (2).

Since use as a control material would require exposure of $\mathrm{Eu}_{2} \mathrm{O}_{3}$ to elevated temperatures, a complete knowledge of its high temperature physical properties is necessary. Low room temperature Young's modulus values have been reported (3), and subsequent elevated temperature investigations by Suchome 1 and Hunter (4) have indicated anomalous elastic behavior for large-grained monoclinic $\mathrm{Eu}_{2} \mathrm{O}_{3}$ specimens, both were assumed to be the result of microcracks induced by thermal expansion anisotropies. Suchomel found that hot pressed $\mathrm{Eu}_{2} \mathrm{O}_{3}$ and $\mathrm{HfO}_{2}-$ $\mathrm{Eu}_{2} \mathrm{O}_{3}$ compositions with grain sizes below 8 m exhibited the expected elastic behavior at room temperature and during thermal cycling. Microstructural control of $\mathrm{Eu}_{2} \mathrm{O}_{3}$ by hot pressing or additions of $\mathrm{HfO}_{2}$ as a grain growth inhibitor was necessary to obtain physical characteristics desirable for control rod applications. Suchomel et a1. (5) found that small additions of $\mathrm{Ta}_{2} \mathrm{O}_{5}$ were also effective in suppressing the grain growth associated with sintering $\mathrm{Eu}_{2} \mathrm{O}_{3}$; however, its effect on the elastic properties was not studied. 
There were two primary objectives of this investigation. The first was to relate the elastic properties and internal friction of the selected compositions to the microstructure, and the second, to provide further evidence that grain size controls the microcracking phenomena by comparing the axial thermal expansion anisotropies of $\mathrm{Eu}_{2} \mathrm{O}_{3}$, known to be highly susceptible to grain coarsening, with the axial thermal expansions known for monoclinic $\mathrm{Gd}_{2} \mathrm{O}_{3}(6)$, known to also exhibit anomalous elastic behavior, resultant from microcracking, for specimens with large grain sizes produced by heat treatment (7) . 


\section{LITERATURE SURVEY}

Microcracking is a phenomenon which results from the presence of microstresses associated with thermal expansion anisotropies in non-cubic polycrystalline materials. Lazlo (8) instigated the use of the microstress theory to explain microcracking. Buessem (9) further refined the theory to statistically account for the random crystallographic orientation of the grains and the thermal expansion mismatches. His calculated normal stresses, $\sigma_{n}^{1,2}$, between two grains, designated 1 and 2 , are represented by the equation

$$
\sigma_{n}^{1,2}=\frac{\alpha_{1}^{n}+\alpha_{2}^{n}}{2} E \cdot \Delta T
$$

where $\alpha_{1}^{n}$ and $\alpha_{2}^{n}$ are the normal components of the thermal ex pansion coefficients between grains 1 and 2 ,

$E$ is the Young's modulus, and

$\Delta \mathrm{T}$ is the cooling temperature difference.

Microstress calculations by Likhachev (10) indicated that grain size should have no effect on microcracking; however, several experimental investigations indicate that such a relation does exist. Two mathematical approaches to explain this critical grain size-microcracking relation have been formulated by Kuszyk and Bradt (11) and Cleveland and Bradt (12).

The first model relating a critical grain size to microcrack formation, derived by Kuszyk and Bradt, is based on an energy criterion which assumes that thermal expansion micro- 
stresses and microcrack formation sites are available in the body. Upon cooling, thermal expansion anisotropies produce a stored elastic strain energy per unit volume. Some of the strain energy can be relieved by microcrack formation, which is manifested as a surface energy term. The total energy of the system can be expressed by the equation

$$
\text { Total energy }=N_{S}(S . E .) l^{3}+N_{c}\left(-\gamma_{f}\right) l^{2}
$$

where $\mathrm{N}_{\mathrm{s}}$ and $\mathrm{N}_{\mathrm{c}}$ are the average number of strained and microcracked grains,

S.E. is the average stored elastic strain energy per unit volume resulting from thermal expansion anisotropy, $\gamma_{f}$ is the average fracture surface energy, and

$\ell$ is the average grain size,

which represents the sum of the stored strain energy and the surface energy related to the microcrack fracture surfaces. A critical grain size, $\ell_{c}$, can be calculated by differentiating the total energy equation with respect to $\ell$ and setting the new expression equal to zero. Rearranging the terms and solving for $l_{c}$, the equation becomes

$$
\ell c=\frac{2 N_{c}\left(\gamma_{f}\right)}{3 N_{S}(S . E .)}
$$

The Cleveland and Bradt (12) critical grain size - microcracking relation, the second model, uses thermal expansion anisotropies and takes the form 


$$
\ell_{c}=\frac{14.4 \gamma f}{E \cdot \Delta \alpha_{\max }^{2} \Delta \mathrm{T}^{2}}
$$

where $\gamma f$ is the average fracture surface energy,

E is Young's modulus,

$\Delta \alpha_{\max }$ is the maximum difference in thermal expansion coefficients along crystallographic axis of the unit ce11, and

$\Delta \mathrm{T}$ is the assumed temperature range over which micro= stresses are relieved by microcracking.

Several anisotropic oxides are known to exhibit anomalous elastic behavior. Manning (13) found anomalous elastic behavior for monoclinic $\mathrm{Nb}_{2} \mathrm{O}_{5}$ and attributed it to microcrack healing and formation. Hot pressed specimens with grain sizes smaller than sintered specimens exhibited expected room temperature modulus values, while the larger grained sintered specimens had modulus values markedly lower. Thermal cycling of the small-grained hot-pressed specimens exhibited a 1inear relation between elastic modulus and temperature while the larger grained sintered specimens behaved anomalously, producing a hysteresis 10op. Examination of the high temperature $x$-ray axial thermal expansion coefficients showed a maximum difference of $5 \times 10^{-6 \circ} \mathrm{C}^{-1}$, and the expansion anisotropies were assumed to be responsible for microcrack formation.

Two conflicting reports exist for the elastic behavior of monoclinic $\mathrm{Gd}_{2} \mathrm{O}_{3}$. Haglund and Hunter (14) found a linear rela- 
tion between elastic modulus and temperature, while Dole and Hunter (7), observed a hysteresis effect for elastic modulus when monoclinic $\mathrm{Gd}_{2} \mathrm{O}_{3}$ was thermally cycled. Microstructural examination revealed that Haglund's specimens had an average grain size of $13 \mu \mathrm{m}$ while Dole's specimens were $145 \mu \mathrm{m}$ in size. Dole and Hunter theorized that the larger grain size $\mathrm{Gd}_{2} \mathrm{O}_{3}$ specimens had exceeded the critical grain size for microcrack formation, and the presence of the microcracks was responsible for the low room temperature elastic modulus values and the hysteresis elastic behavior displayed by the specimens when they were thermally cycled. For different crystallographic directions the thermal expansion coefficients differ by a maximum of approximately $5 \times 10^{-6}{ }^{\circ} \mathrm{C}^{-1}(6)$.

Suchomel and Hunter (4) found that sintered monoclinic $\mathrm{Eu}_{2} \mathrm{O}_{3}$ specimens with grain sizes of $117 \mu \mathrm{m}$ had abnormally low room temperature elastic moduli. Curtis and Tharp (3) had also indicated that $\mathrm{Eu}_{2} \mathrm{O}_{3}$ had a low room temperature modulus. Suchomel and Hunter, however, found that a hot-pressed specimen with an average grain size of $5 \mu \mathrm{m}$ had the expected room temperature elastic modulus when corrected for the effects of porosity. The larger-grained sintered specimens contained a sufficient degree of microcracking to lower the elastic modulus, while the smaller-grained hot pressed specimens did not, hence the expected modulus. The grain size of sintered monoclinic $\mathrm{Eu}_{2} \mathrm{O}_{3}$ was further controlled by additions of $\mathrm{HfO}_{2}$. As additions of $\mathrm{HfO}_{2}$ were increased, inhibiting grain growth, the 
size of the hysteresis loop formed by plotting Young's modulus for a heating-cooling cycle decreased. A linear elastic modulus relation for thermal cycling was found when additions of $6 / \mathrm{m} / \mathrm{o} \mathrm{HfO}_{2}$. inhibited grain growth enough that microcracking did not occur, and microstructural examination revealed the critical size to be $8 \mu \mathrm{m}$.

Siebeneck et al. (15) found that thermal diffusivity is also affected by microcracking in anisotropic polycrystalline ceramics. Microcracking in the large grained $\mathrm{Fe}_{2} \mathrm{TiO}_{5}$ reduced thermal diffusivity by a factor of 3 , which is more significant than the detrimental effects that porosity has on thermal diffusivity. Specimens with a grain size below $1 \mu \mathrm{m}$ did not exhibit the behavior associated with microcracking.

Several other titanates exhibit behavior representative of the microcracking phenomena. Matsuo and Sasaki (16) studied the effect of composition on grain size and mechanical properties for several bodies. When additions were large enough to suppress the grain size to $1 \mu \mathrm{m}$, the strength increased. Bush and Hummel (17) found that $\mathrm{MgTi}_{2} \mathrm{O}_{5}$ displayed anomalous Young's modulus upon thermal cycling. Kuszyk and Bradt (11) expanded this investigation and found the critical grain size to be $3 \mu \mathrm{m}$.

Critical grain sizes for microcracking in several orthorhombic pseudobrookite structures have recently been determined (12). Thermal expansion, internal friction, elastic 
modulus, and flexural strength all exhibited behaviors indicative of microcracking for coarser grained specimens. Critical grain sizes were $5 \mu \mathrm{m}$ and $3 \mathrm{\mu m}$ for the $\mathrm{MgTi}_{2} \mathrm{O}_{5}$ and $\mathrm{Fe}_{2} \mathrm{TiO}_{5}$, respectively.

Rutile, $\mathrm{TiO}_{2}$, has shown evidence of microcracking. Kirchner and Gruver (18) found that for specimens with grain sizes greater than $20 \mu \mathrm{m}$ cracks formed during cooling and re= sulted in abnormal strength behavior at room temperature. Charvat and Kingery (19) found that cracking in $28 \mu \mathrm{m}$ grain sized specimens produced the anomalous thermal expansion behavior associated with microcracking when thermally cycled. A more comprehensive investigation by McPherson (20) found the critical grain size for microcracking to be approximately $8 \mu \mathrm{m}$.

Dole et al. (21) investigated the elastic properties of monoclinic $\mathrm{HfO}_{2}$ at room temperature and developed a critical grain size-microcracking relation. Young's modulus values for specimens with grain sizes in excess of $3 \mu \mathrm{m}$ were abnormally low. Internal friction values for large grain size specimens were anomalously high contradicting the theoretical postulate that internal friction is inversely proportional to the average grain size (22). High temperature $x$-ray investigations (23) showed that monoclinic $\mathrm{HfO}_{2}$ has anisotropic thermal expansion, which led Dole et a1. to assume that the microstrains developed in the large grained specimens resulted in microcracking. Continuation of the study at high 
temperature showed that $\mathrm{HfO}_{2}$ specimens with grain sizes greater than $3 \mu \mathrm{m}$ exhibited hysteresis of Young's modulus and internal friction relations with temperature while specimens below $3 \mu \mathrm{m}$ did not exhibit hysteresis for either Young's modulus or internal friction (24). High temperature $x$-ray studies have revealed no polymorphic transformation for monoclinic $\mathrm{HfO}_{2}$ between $25^{\circ} \mathrm{C}$ and $1500^{\circ} \mathrm{C}$, the investigated temperature range, and therefore the microcracking phenomena was a plausible explanation of the anomalous behavior. As evidenced in all these studies, a critical grain size-microcracking relation occurs in many anisotropic polycrystalline materials. Above this grain size, each material behaves abnormally. 
EXPERIMENTAL PROCEDURE

Specimen Fabrication

Europia $\left(\mathrm{Eu}_{2} \mathrm{O}_{3}\right)$ with a purity of $99.999 \%$ was obtained from Molycorp. Tantalum pentachloride, the only soluble tantalum compound, with a purity of $99.9 \%$ was obtained from Research Organic/Inorganic Corporation. A coprecipitation technique was used to obtain small particle size, homogeneous mixing, and restrict the number of impurities. The europia was dissolved in a hot nitric acid-water solution and the $\mathrm{TaCl}_{5}$ was dissolved in anhydrous methanol and further diluted with $\mathrm{H}_{2} \mathrm{O}$. Both solutions were quantitatively analyzed by the Ames Laboratory Analytical Chemistry Group.

Two specimens of each composition $0.5,1.0,1.5,2.0$, $4.0,6.0$, and 10.0 a/o Ta cation substitution for $\mathrm{Eu}$ in $\mathrm{Eu}_{2} \mathrm{O}_{3}$ were formulated by mixing the tantalum and europium solutions in the proper proportions. The mixture was precipitated in an aqueous ammonia solution. The precipitate was vacuum filtered in a fritted filter and washed with water to remove the excess ammonia. Water removal was accomplished by washing the precipitate with successive applications of acetone, toluene, and acetone producing a highly sinterable powder. The filter cake was ground to -100 mesh in a preheated $\left(100^{\circ} \mathrm{C}\right)$ mortar and pestle, which vaporized the residual acetone, producing a friable powder.

All the powders were calcined at $965^{\circ} \mathrm{C}$ for 1 hour. Approximately 20 grams of calcined powder were placed in a 
double action steel die with an $8.56 \times 0.56 \mathrm{~cm}$ cavity and pressed at $1750 \mathrm{psi}$ for $30 \mathrm{sec}$. The rectangular prism was removed, placed in a rubber container, and densified further by isostatic pressing at 30,000 psi for $30 \mathrm{sec}$.

The rectangular prisms were sintered in a gas-fired Lemont muffle furnace utilizing an oxidizing atmosphere of gas and air to $1300^{\circ} \mathrm{C}$. Above $1300^{\circ} \mathrm{C}$ an oxygen gas mixture was used. The specimens were fired for $1 \mathrm{hr}$ at $1800^{\circ} \mathrm{C}$. In an attempt to study the effects of grain growth, a selected specimen from each composition which had been previously fired at $1800^{\circ} \mathrm{C}$ was refired at $1900^{\circ} \mathrm{C}$ for $1 \mathrm{hr}$.

Specimen shape became irregular during firing, therefore, a silicon carbide surface grinder was used to machine the bars into rectangular prisms with tolerances of $\pm 0.001 \mathrm{~cm}$. The machined specimens were approximately $5.0 \mathrm{~cm} \times 0.6 \mathrm{~cm} \times$ $0.225 \mathrm{~cm}$. Bulk density was determined from the bar's mass and dimensions. X-ray diffraction provided phase identification in each fired specimen.

Elastic modulus and internal friction determinations along with $x$-ray diffraction and microstructural analyses were the major tests carried out in this work.

\section{Elasticity Measurements}

The sonic resonance technique described by forster (25) was used to determine the elastic moduli. The modulus equipment, more fully described by Marlowe (26), was used to 
measure the resonant frequencies of the specimen. Cotton strings suspended the rectangular specimen horizontally from a magnetic record cutting head (driver) and a phonograph pickup. An electronic signal produced by a frequency generator was amplified and converted into mechanical vibrations, allowed to pass through the specimen, and converted from a mechanical to an electronic signal by the pickup. This signal was amplified and monitored by a digital frequency counter, vacuum tube voltmeter, and oscilloscope. Resonant frequencies were found to be the strongest signals and the mode of vibration was determined by probing the specimen with a blunt instrument to determine nodal plane locations.

Elevated temperature data were obtained by suspending the specimen horizontally by carbon yarn in the hot zone of a vacuum $\left(5 \times 10^{-4}\right.$ tor $\left.r\right)$ carbon-rod resistance furnace. The manually controlled temperature was monitored by a Pt-90\% Pt $10 \%$ Rh thermocople. Specimens were allowed to thermally equilibrate for 45 minutes after each power setting change. The flexural and torsional frequencies were determined over the range from room temperature to $1500^{\circ} \mathrm{C}$, with the temperature being raised by $100^{\circ} \mathrm{C}$ increments.

The resonance frequency data were converted into moduli values by using the equations of Pickett (27) as modified by Hasselman (28). Shear modulus, G, was calculated directly from the equation 


$$
G=\frac{4 \operatorname{LRmf} f_{t}^{2}}{s}
$$

where $L$ is the length of the specimen,

$\mathrm{m}$ is the mass of the specimen,

$f_{t}$ is the fundamental torsional resonant frequency,

$S$ is the area of the cross section of the specimen, and

$\mathrm{R}$ is a shape factor.

Young's modulus, E, for a rectangular specimen can be calculated from the equation

$$
E=0.94645 \frac{\mathrm{Cmf}_{\mathrm{f}}^{2}}{\mathrm{~B}}
$$

where $f_{f}$ is the fundamental flexural resonant frequency,

$B$ is the length of the cross section perpendicular to the vibration direction, and

$C$ is a shape factor.

The shape factor, $C$, is a function of Poisson's ratio, $\mu$, which is related to both the shear and Young's modulus by the equation

$$
\mu=\frac{E}{2 G}-1
$$

Since the shape factor, $C$, contains Poisson's ratio, $\ddot{\mu}$, Equations 5,6 , and 7 must be solved in an iterative manner to calculate Young's modulus, E.

Accurate high temperature modulus expressions formulated by Hasselman (28) are necessary to account for thermal expansion of the test specimen. The modulus at temperature, $\mathrm{M}_{\mathrm{T}}$, 
is given in the form

$$
M_{T}=M_{0} \frac{f_{t}^{2}}{f_{0}^{2}} \frac{1}{1+\alpha \Delta T}
$$

where $M_{0}$ is the modulus at room temperature,

$f_{t}$ is the resonant frequency at temperature $T$,

$f_{0}$ is the resonant frequency at room temperature,

$\alpha$ is the coefficient of 1 inear thermal expansion, and

$\Delta \mathrm{T}$ is the difference between room temperature and temperature $(\mathrm{T})$.

Internal Friction Measurements

Internal friction $\left(Q^{-1}\right)$ was determined over the temperature range from room temperature to $1500^{\circ} \mathrm{C}$. The technique involved determining the rate of decay of amplitude in free vibration. The $\mathrm{Q}^{-1}$ analyzer was designed and built by the Ames Laboratory Electronics Group with a similar system being described in the 1iterature by Razumov and Postnikov (29).

With the specimen being driven at its flexural resonant frequency the driving signal is turned: off and the number of cycles, $N$, between a fixed amplitude, $A$, and a smaller fixed amplitude, $B$, is counted by the $Q^{-1}$ system. The measured internal friction, $Q_{m}^{-1}$, is given by

$$
Q_{m}^{-1}=\frac{\ln (A / B)}{\pi N}
$$

and choosing amplitudes such that $A / B=e$, simplifies Equation 9 to 


$$
Q_{m}^{-1}=\frac{1}{\pi N} \text {. }
$$

The measured internal friction, $Q_{m}^{-1}$, is composed of the internal frictions of the specimen, $Q_{S}^{-1}$, and the apparatus, $Q_{a}^{-1}$. The internal friction of the apparatus includes the effects of suspension position with relation to the nodal positions. Wachtman and Tefft (30) have formulated an equation relating all of these quantities such that the measured internal friction, $Q_{m}^{-1}$, is

$$
Q_{m}^{-1}=\frac{Q_{s}^{-1}+k Q_{a}^{-1}\left(Y / Y_{o}\right)^{2}}{1+k\left(Y / Y_{o}\right)^{2}:}
$$

where $Q_{S}^{-1}$ is the internal friction of the specimen, $k$ is an empirical constant,

$\mathrm{Q}_{\mathrm{a}}^{-1}$ is the internal friction of the apparatus,

$Y$ is the vertical displacement of the suspension point from equilibrium, and

$Y_{0}$ is the vertical displacement of the end of the specimen.

The $Y / Y_{0}$ term is given by Rayleigh, cited in (30), for the transverse fundamental mode of vibration as

$$
\begin{aligned}
Y / Y_{O}= & {[1.018(\cosh 4.730 x / \ell+\cos 4.730 x / \ell)} \\
& -(\sinh 4.730 x / \ell+\sin 4.730 x / \ell)] \cdot \frac{1}{2.036}
\end{aligned}
$$

where $l$ is the length of the specimen, and $x$ is the distance to the suspersion point from the end of the specimen. 
Using cotton strings, three different horizontal suspension points, $x$, were used to determine three $Q_{m}^{-1}$. Three equations in the form of Equation 11 for $Q_{m}^{-1}$ were solved simultaneously to provide values for $Q_{a}^{-1}, k$ and $Q_{S}^{-1}$. All of these initial determinations of $\mathrm{Q}_{S}^{-1}$ were made at room temperature and in air, neglecting the damping effect of air since $Q_{S}^{-1}$ values were relatively large when compared to the effect of $\operatorname{air}(30)$.

With the specimen suspended horizontally by carbon strings in the furnace, as described in the elasticity section, high temperature internal friction measurements were made. Since only one suspension point was used for elevated temperature internal friction measurements, these values were corrected to the specimen room temperature corrected internal friction value, $Q_{S}^{-1}$, by the equation

$$
Q_{s T}^{-1}=Q_{s}^{-1}\left(\frac{Q_{m T}^{-1}}{Q_{0}^{-1}}\right)
$$

where $Q_{S T}^{-1}$ is the measured specimen corrected internal friction at elevated temperature,

$\mathrm{Q}_{\mathrm{mT}}^{-1}$ is the measured internal friction at elevated temperature, and

$\mathrm{Q}_{0}^{-1}$ is the measured internal friction with carbon strings in vacuum at room temperature.

The assumption inherent in this equation is that all of the change in observed internal friction as the temperature is 
increased is attributable to the specimen.

\section{X-ray Diffraction Measurements}

Both $\mathrm{Eu}_{2} \mathrm{O}_{3}$ (4) and $\mathrm{Gd}_{2} \mathrm{O}_{3}$ (7) have exhibited elastic behavior indicative of microcracking. The difference is that grain sizes large enough to produce the elastic modulus microcracking behavior in $\mathrm{Gd}_{2} \mathrm{O}_{3}$ (7) have required extensive thermal treatment to promote grain growth, while grain coarsening (31) in $\mathrm{Eu}_{2} \mathrm{O}_{3}$ during sintering produced large enough grains so the specimen exhibited the microcrack-related elastic behavior. In an effort to determine if grain size was the controlling factor for microcracking, and not a large difference between thermal expansion anisotropies for $\mathrm{Eu}_{2} \mathrm{O}_{3}$ and $\mathrm{Gd}_{2} \mathrm{O}_{3}$, the axial thermal expansion values for $\mathrm{Eu}_{2} \mathrm{O}_{3}$. were measured and compared with the literature values for $\mathrm{Gd}_{2} \mathrm{O}_{3}$, an oxide of similar crystal structure and physical characteristics.

A Norelco wide range diffractometer and Materials Research Corporation model $x-86-\mathrm{N} 3$ furnace attachment were used. Major diffraction peaks were scanned at a rate of $1 / 2^{\circ} 2 \theta$ per minute.

The $\mathrm{Eu}_{2} \mathrm{O}_{3}$ powder used for $x$-ray diffraction was fired at $1800^{\circ} \mathrm{C}$ in the same manner as the modulus specimens, ground to - 325 mesh, and suspended in acetone. The acetone-powder suspension was placed on a $60 \% \mathrm{Pt}-40 \% \mathrm{Rh}$ stage heating element and the acetone was allowed to vaporize. Temperature was 
monitored by a Pt-87\% Pt $13 \%$ Rh thermocouple. Johnstone (32) and Stacy (33) provide a more detailed equipment description. Stage alignment was checked by comparing room temperature diffraction peak locations and hkl planar index values for $\mathrm{Eu}_{2} \mathrm{O}_{3}$ with those given by Campbe11 (34). Manning found that thermal cycling of the stage and specimen had no effect on the alignment. Specimens were allowed to come to thermal equilibrium for 15 minutes after each power setting change. Measurements were made from room temperature to $1000^{\circ} \mathrm{C}$. Lattice parameters were calculated by a Fortran lattice constant refinement program, LCR-2, developed by Williams (35). The program refined the constants by a least squares method and in this case, the Nelson-Riley extrapolation functions was used.

\section{Microstructura1 Analysis}

Each specimen was sectioned for microstructural analyses and polished with a successive series of silicon carbide papers and fine alumina abrasives. Polished surfaces were etched with a $3: 1 \quad \mathrm{H}_{2} \mathrm{SO}_{4}: \mathrm{H}_{2} \mathrm{O}$ solution and examined with reflected light microscopy in the normal and phase contrast modes. Average grain size was calculated by the Fullman (36) linear intercept method. 


\section{RESULTS AND DISCUSSION}

Specimens with specific compositions will be referred to in the text by a/o Ta with the understanding that the bulk of the composition is $\mathrm{Eu}_{2} \mathrm{O}_{3}$. The Ta is used as a cation substitute for the Eu. Firing at $1800^{\circ} \mathrm{C}$ will be referred to as initially fired and specimens subjected to a refiring at $1900^{\circ} \mathrm{C}$ will be identified as refired specimens. Table 1 1ists a number of parameters for each of the fired and refired specimens.

The table illustrates the grain size-composition interdependency and the progressive effects they have on the elastic behavior.

\section{Microstructural Effects on Elastic Modulus}

Porrosity

Different porosity levels in materials will directly affect their modulus values and has been well established for the rare earth oxides (37) that the equation

$$
M=M_{0}(1-b P)
$$

where $M_{0}$ is the modulus at zero porosity,

$M$ is the observed modulus,

$\mathrm{b}$ is an empirical constant, and

$P$ is the volume fraction porosity.

best illustrates porosity related modulus behavior. Wachtman (38) and Manning et al. (37) have experimentally found $b$ to have a value of 2.0 while Hasselman and Fulrath (39) have theoretically determined it to be 2. Examination of Table 1 shows that most of the initially fired specimens have little 
Table 1. Physical characteristics of fired and refired $\mathrm{Ta}_{2} \mathrm{O}_{5} \mathrm{Eu}_{2} \mathrm{O}_{3}$ compositions at room temperature

\begin{tabular}{|c|c|c|c|c|c|c|c|c|c|}
\hline \multicolumn{2}{|c|}{$\begin{array}{l}\text { Composition } \\
\text { a/o Ta }\end{array}$} & \multicolumn{2}{|c|}{$\begin{array}{l}\text { Average grain } \\
\text { size, } \mu \mathrm{m} \\
\text { Specimen } \\
\text { A } \quad \text { B. }\end{array}$} & \multicolumn{2}{|c|}{$\begin{array}{c}\text { Internal friction } \\
\times 10^{-4} \\
\text { Specimen }\end{array}$} & \multicolumn{2}{|c|}{$\begin{array}{c}\text { Anomalous behavior } \\
\text { yes or no }\end{array}$} & \multicolumn{2}{|c|}{$\begin{array}{c}\text { Density } \\
\text { g/ } \mathrm{cm}^{3} \\
\text { Specimen }\end{array}$} \\
\hline \multicolumn{10}{|l|}{ As $f$} \\
\hline & 0.5 & 29.86 & 30.50 & 5.7 & 7.6 & yes & large & 7.81 & \\
\hline & 1.0 & 75.43 & 30.84 & 6.84 & & yes & med. & 7.90 & 7.56 \\
\hline & 1.5 & 19.23 & 14.34 & 2.14 & 1.89 & yes & $\operatorname{sma} 11$ & 7.77 & 7.83 \\
\hline & 2.0 & 13.40 & 9.71 & 5.49 & 2.22 & no & & 7.72 & \\
\hline & 4.0 & 9.11 & 11.50 & 1.21 & 1.41 & no & & 7.57 & 7.80 \\
\hline & 6.0 & 5.71 & 9.12 & 1.78 & & no & & 7.63 & 7.82 \\
\hline & 10.0 & 6.21 & 7.43 & 1.64 & 2.82 & no & & 7.43 & 7.54 \\
\hline \multicolumn{10}{|l|}{ As $r$} \\
\hline & 0.5 & \multicolumn{2}{|c|}{48.02} & \multicolumn{2}{|c|}{54.85} & yes & $\operatorname{large}$ & \multicolumn{2}{|c|}{7.82} \\
\hline & 1.0 & \multicolumn{2}{|c|}{38.45} & \multicolumn{2}{|c|}{33.95} & yes & large & \multicolumn{2}{|c|}{7.85} \\
\hline & 1.5 & \multicolumn{2}{|c|}{21.87} & \multicolumn{2}{|c|}{6.93} & yes & med. & \multicolumn{2}{|c|}{7.85} \\
\hline & 2.0 & \multicolumn{2}{|c|}{$\cdots$} & \multicolumn{2}{|c|}{$\cdots$} & $=--$ & & \multicolumn{2}{|c|}{$--\cdot$} \\
\hline & 4.0 & \multicolumn{2}{|c|}{15.68} & \multicolumn{2}{|c|}{5.74} & yes & med. & \multicolumn{2}{|c|}{7.37} \\
\hline & 6.0 & \multicolumn{2}{|c|}{9.94} & \multicolumn{2}{|c|}{1.87} & no & & \multicolumn{2}{|c|}{7.75} \\
\hline & 10.0 & \multicolumn{2}{|c|}{8.23} & \multicolumn{2}{|c|}{2.55} & no & & \multicolumn{2}{|c|}{7.84} \\
\hline
\end{tabular}


deviation in density, hence, a negligible difference in porosity. All the initially fired and refired specimens with the exception of the $\mathrm{Eu}_{2} \mathrm{O}_{3}$ with 10.0 a/O Ta cation substitution composition, elastic moduli were not affected by the porosity in the specimen. The 10.0 a/o $\mathrm{Ta}$ refired specimen exhibited an increase in density from $7.43 \mathrm{~g} / \mathrm{cc}$ to $7.84 \mathrm{~g} / \mathrm{cc}$, indicative of densification which explains the increase from 1428 kbars for the initially fired specimen to 1559 kbars for the refired specimen. Assuming that the bulk density of the specimen was not affected by second phase precipitation and remained approximately equal to that of monoclinic $\mathrm{Eu}_{2} \mathrm{O}_{3}$, the elimination of approximately $5 \%$ porosity would increase the modulus to 1586 kbars when Equation 14 is applied and $b$ is assumed to be equal to 2 which is in agreement with the observed results.

Grain size

Wachtman (40) had originally stated that elastic modulus should be insensitive to grain size, however several investigations have linked anomalous elastic behavior of anisotropic polycrystalline solids to a critical grain size-microcracking relation. Kuszyk and Bradt (11) and more recently Cleveland and Bradt (12) have shown experimental support for their two theories that a critical grain size microcrack formation relation does exist which causes anomalous behavior in microcracked specimens. It is possible to eliminate microcracking 
and the related behavior by controlling the grain size.

The microstructure (grain size) of $\mathrm{Eu}_{2} \mathrm{O}_{3}$ can be controlled by small additions of $\mathrm{HfO}_{2}$ and $\mathrm{Ta}_{2} \mathrm{O}_{5}$ as described by Suchomel et al. (5), who found that initial firing of pure $\mathrm{Eu}_{2} \mathrm{O}_{3}$ resulted in average grain sizes of $117 \mu \mathrm{m}$. Additions of the two dopants, $\mathrm{HfO}_{2}$ and $\mathrm{Ta}_{2} \mathrm{O}_{5}$, resulted in grain growth suppression and consecutively smaller grained materials as addition levels increased. Figure 1 illustrates the degree of grain growth suppression that the range of additions from 0.50 a/O Ta to 10.0 a/O Ta had on the initial and refired $\mathrm{Eu}_{2} \mathrm{O}_{3}$ specimen. The grain growth suppression results were similar to those found by Suchomel et al., however, the Ta solubility limit was found to be $1.0 \mathrm{a} / \mathrm{o} \mathrm{Ta}$ in this investigation compared to the 1.5 a/o Ta found by Suchomel et al. (5).

For ease in explaining the progressive effect that... compositionally controlled grain size had on the elastic behavior, the compositions are categorized into three sections typified by their elastic behavior. Those specimens exhibiting anomalous elastic behavior are discussed in the first section, the specimens exhibiting linear elastic modulus. temperature relations for the initially fired specimens and anomalous behavior after refiring are discussed in section two, and the specimens exhibiting a linear elastic behavior with temperature for both initially and refired specimens are discussed in the third section. This separation by elastic 


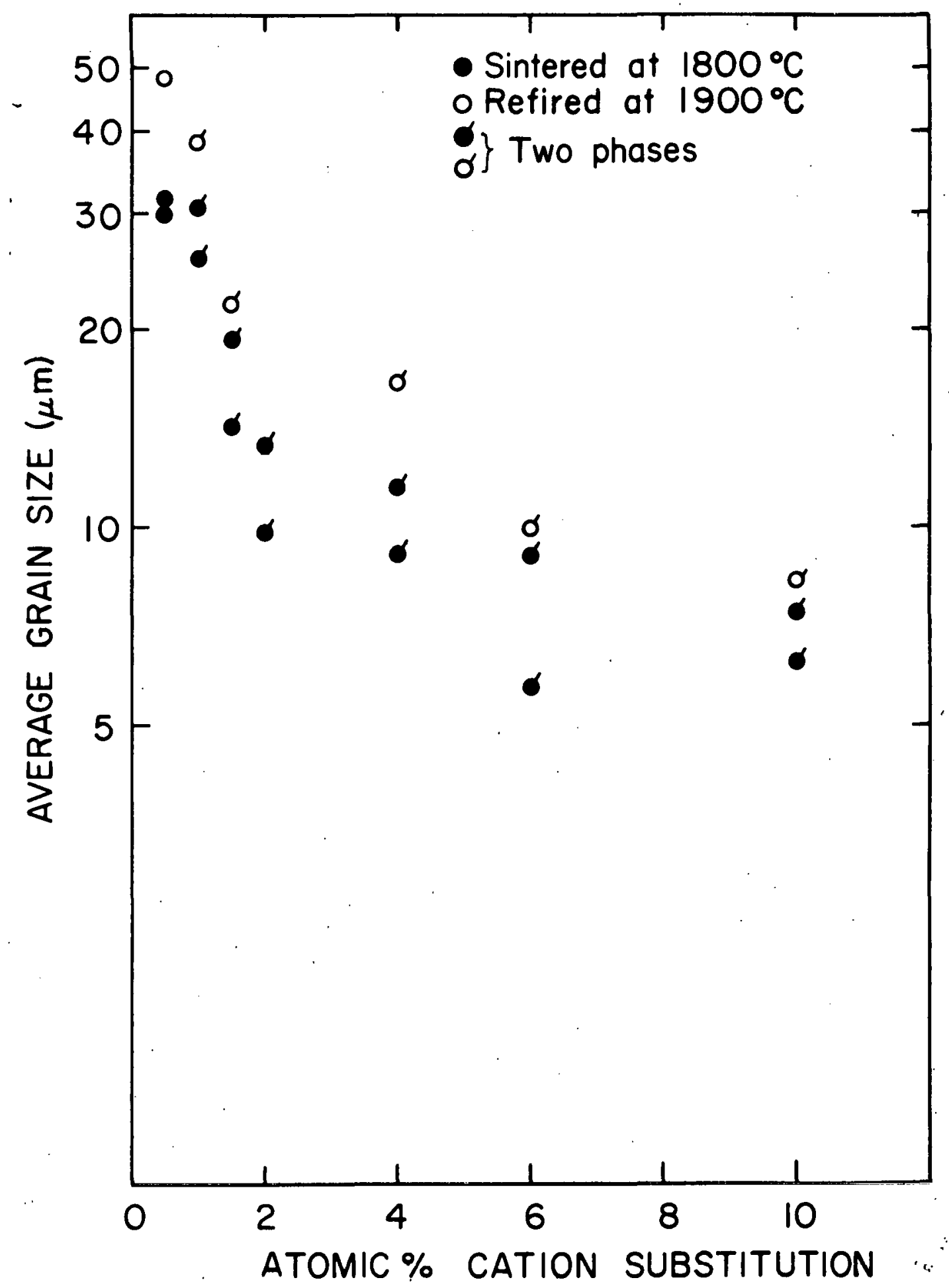

Figure 1. Average grain size of fired and refired $\mathrm{Ta}_{2} \mathrm{O}_{5}$ doped $\mathrm{Eu}_{2} \mathrm{O}_{3}$ compositions 
behaviors is the result of a new theory explaining microcracking-grain size relations, which is a composite of the Kuszyk and Bradt (11) and the Blendell et al. (41) theories. The 3 step behavior can be described as a transition from predominant microstress relaxation by microcracking (Kuszyk and Bradt) to relaxation by creep (Blendell et al.). The grain size dependence of both mechanisms in conjunction with the grain size related anomalous behavior makes the transitory theory attractive.

Due to the progressive decrease in loop size with increasing a/o Ta additions, the heating and cooling Young's modulus plots are listed consecutively in Figures 2-8, and in a simi1ar manner the microstructures are listed in Figures 9-15. The $0.5,1.0$, and $1.5 \mathrm{a} / 0 \mathrm{Ta}$ initially fired specimens exhibited anomalous Young's modulus behavior relative to temperature, assumed to be the result of microcrack presence formed during cooling in the fabrication process, as illustrated in Figures 2, 3, and 4. The size of the hysteresis loop decreases with increasing Ta additions, however, similar structures were found in some of the loops. Figures 2 and 3 refired specimens, represented by open circles, indicate a nonlinear decrease in modulus to approximately $900^{\circ} \mathrm{C}$, where the slope, dE/dT, became positive appearing to indicate that microcracks were healing. This resulted in an increase in Young's modulus. These refired specimens were assumed to be 


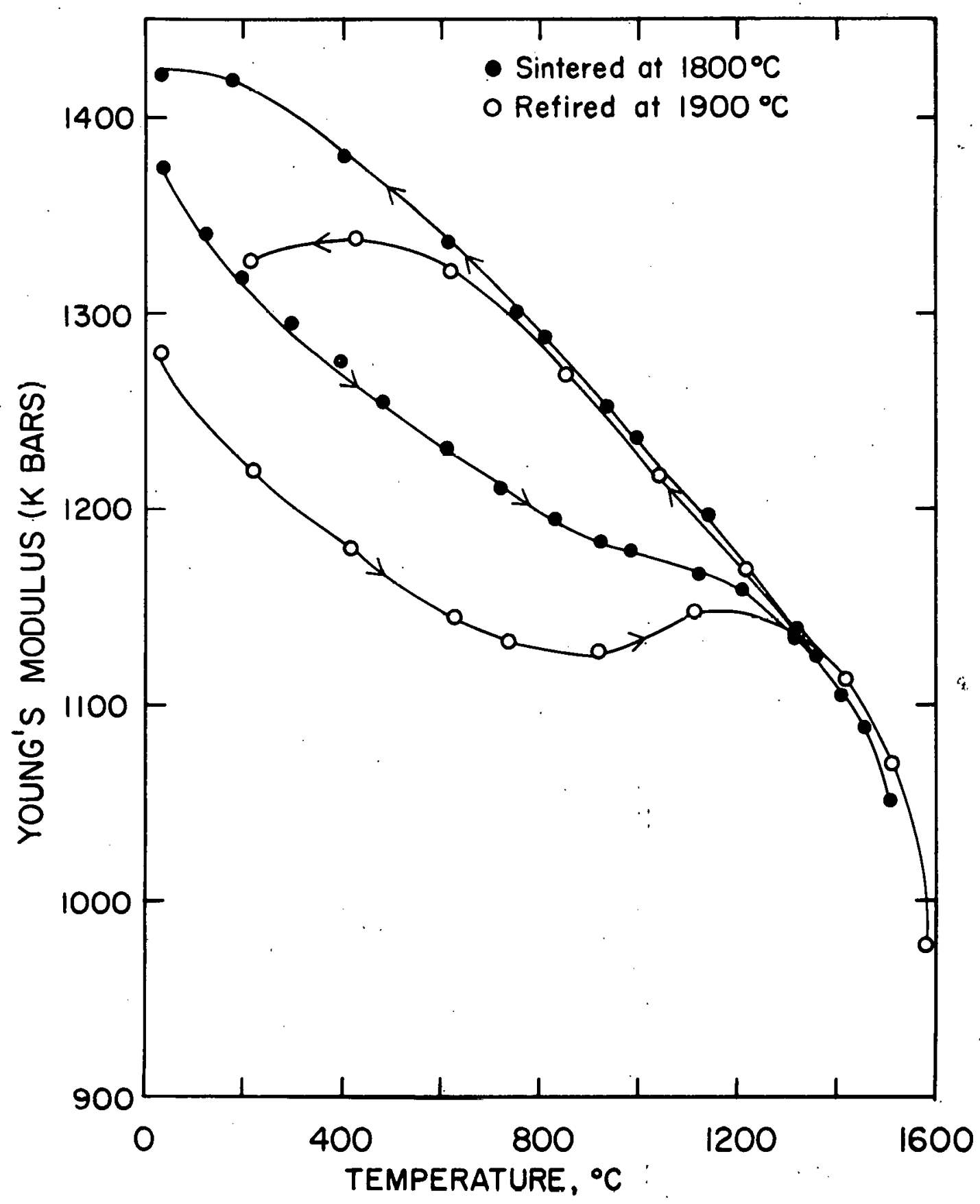

Figure 2. Elevated temperature Young's modulus on heating and cooling for sintered and refired $\mathrm{Eu}_{2} \mathrm{O}_{3}$ with 0.50 a/o Ta cation substitution 


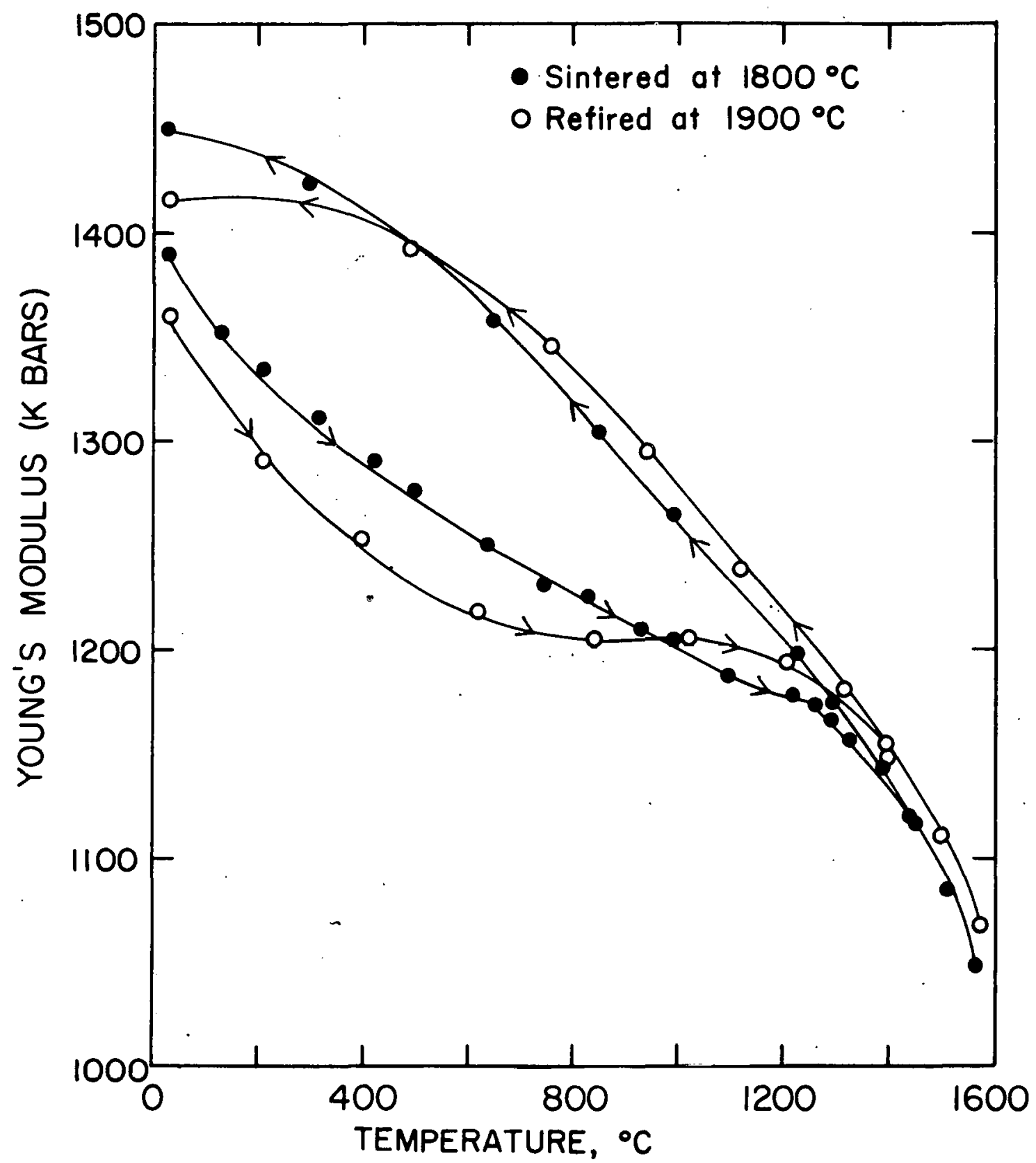

Figure 3. Elevated temperature Young's modulus on heating and cooling for sintered and refired $\mathrm{Eu}_{2} \mathrm{O}_{3}$ with 1.0 a/o Ta cation substitution 


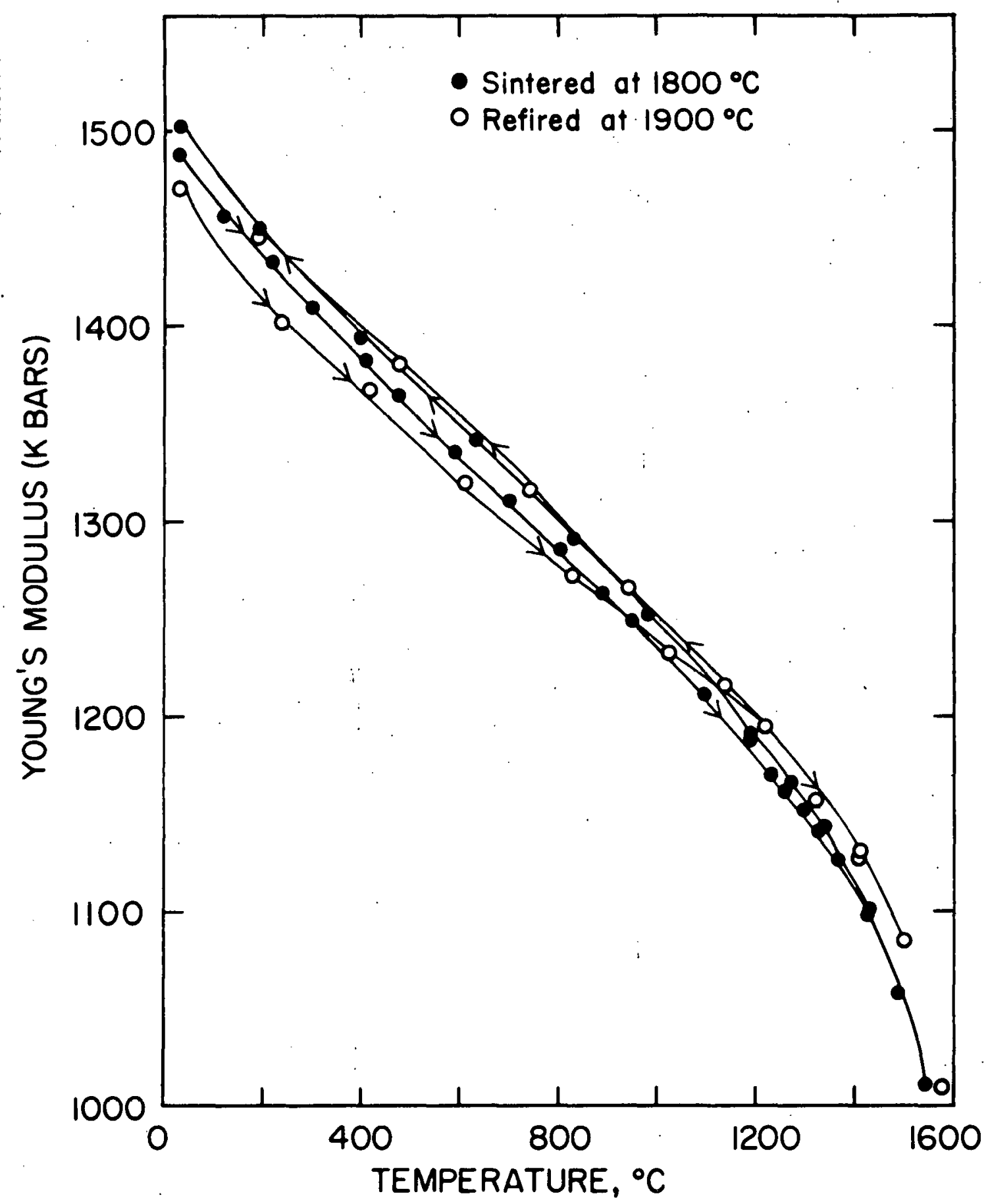

Figure 4: Elevated temperature Young's modulus on heating and cooling for sintered and refired $\mathrm{Eu}_{2} \mathrm{O}_{3}$ with
$1.5 \mathrm{a} / 0 \mathrm{Ta}$ cation substitution 


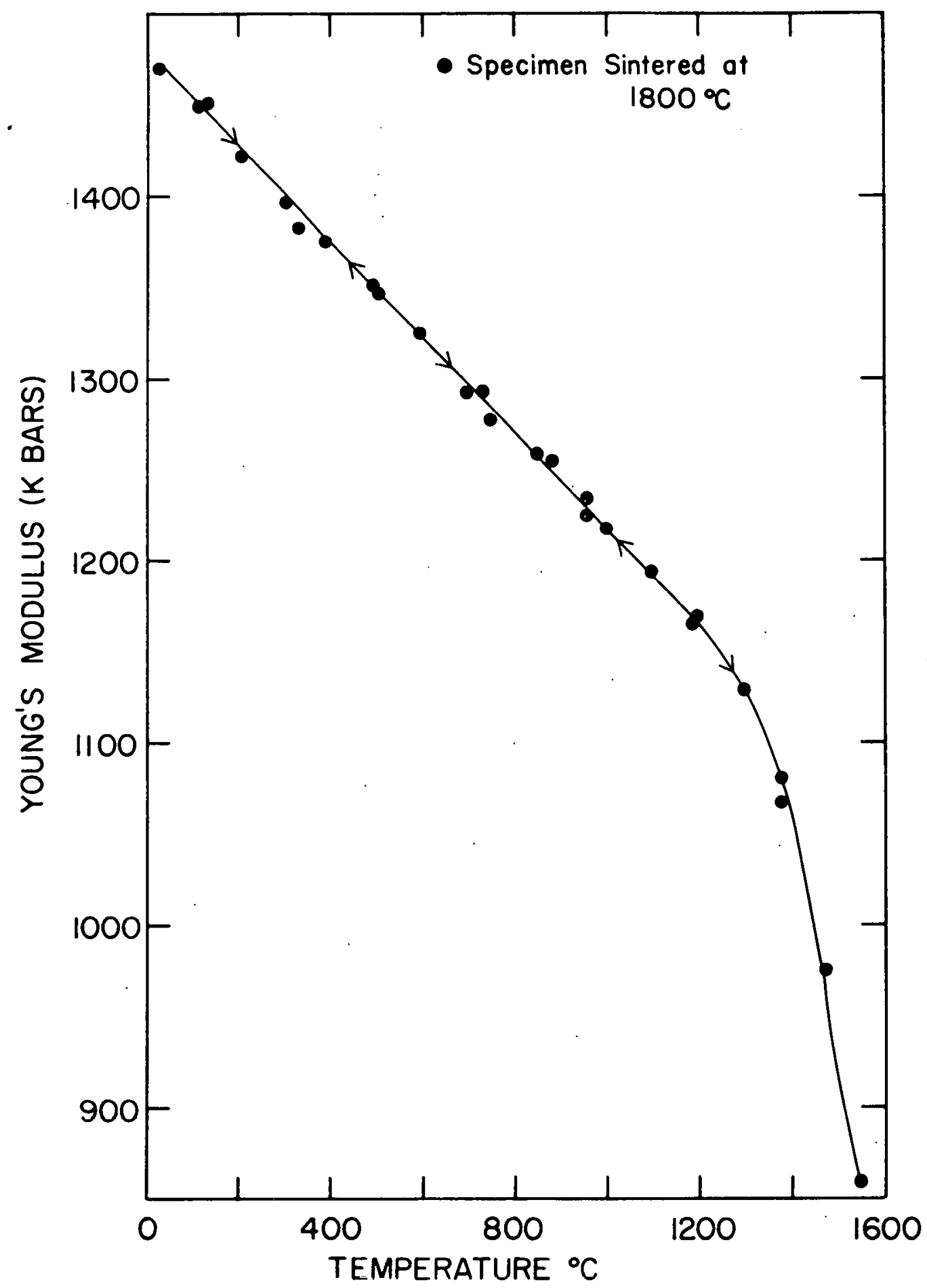

Figure 5. Elevated temperature Young's modulus on heating and cooling for sintered $\mathrm{Eu}_{2} \mathrm{O}_{3}$ with 2.0 a/o Ta 


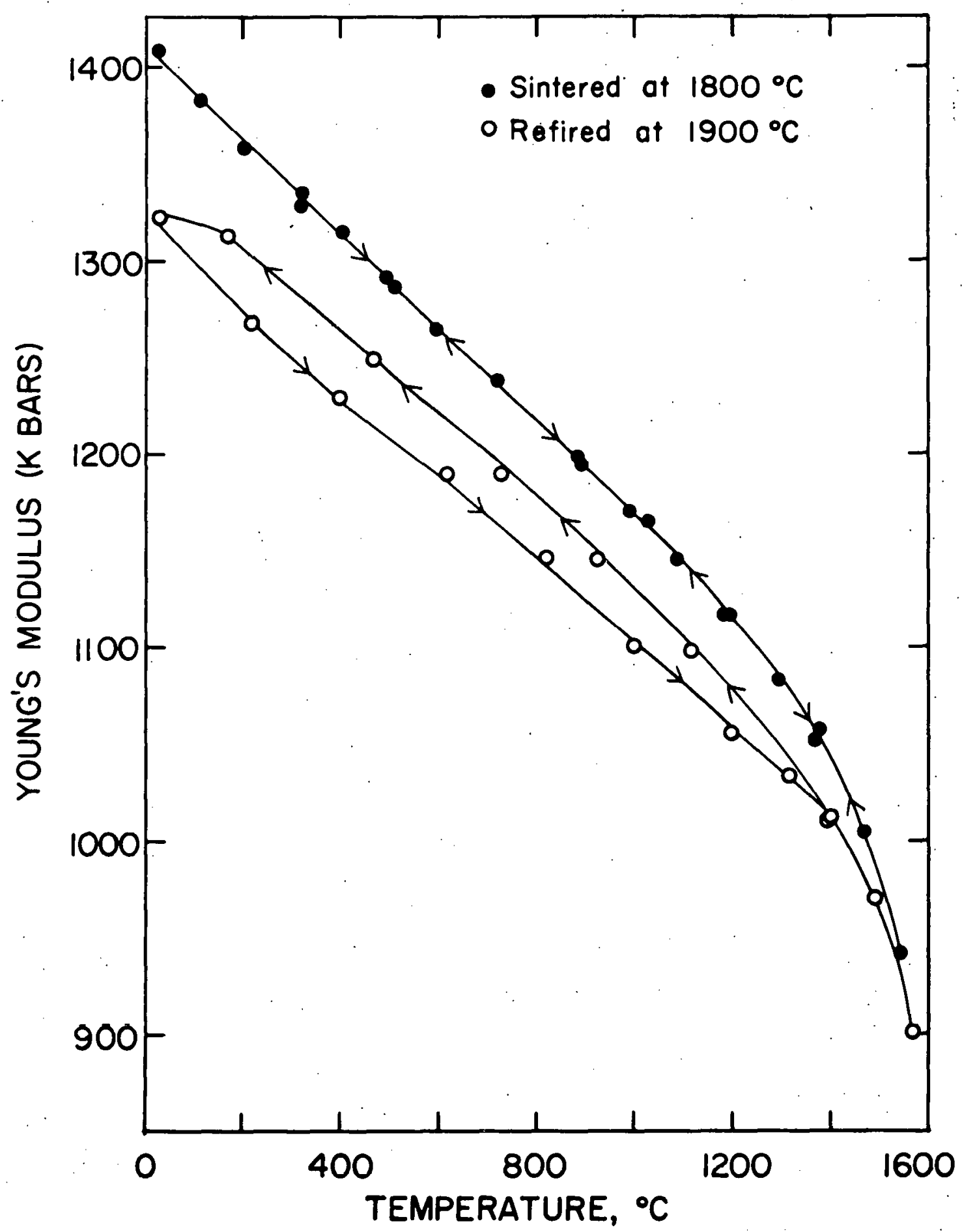

Figure 6. Elevated temperature Young's modulus on heating and cooling for sintered and refired $\mathrm{Eu}_{2} \mathrm{O}_{3}$. with $4.0 \mathrm{a} / 0 \mathrm{Ta}$ cation substitution 


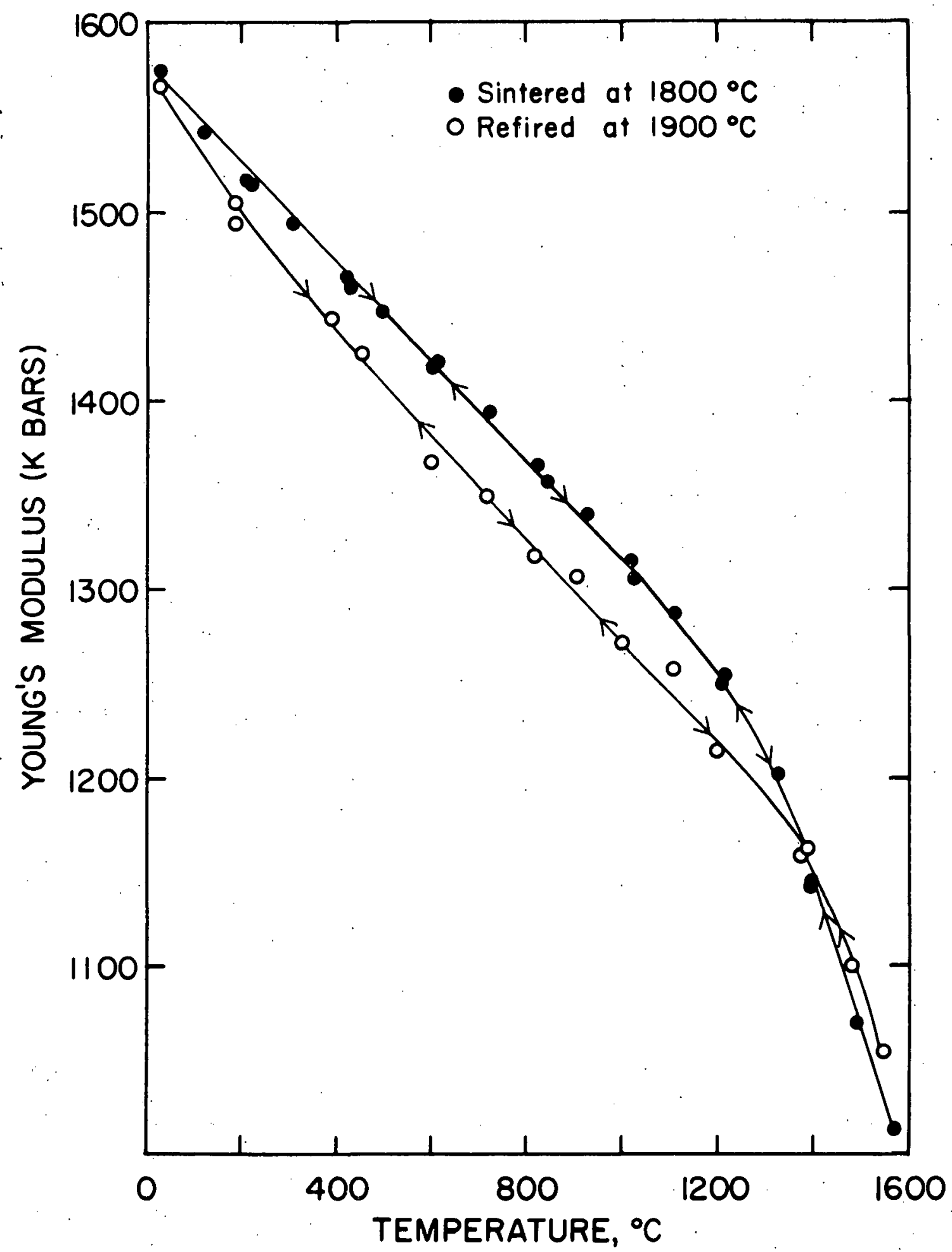

Figure 7. Elevated temperature Young's modulus on heating and cooling for sintered and refired $\mathrm{Eu}_{2} \mathrm{O}_{3}$ with $6.0 \mathrm{a} / \mathrm{0} \mathrm{Ta}$ cation substitution 


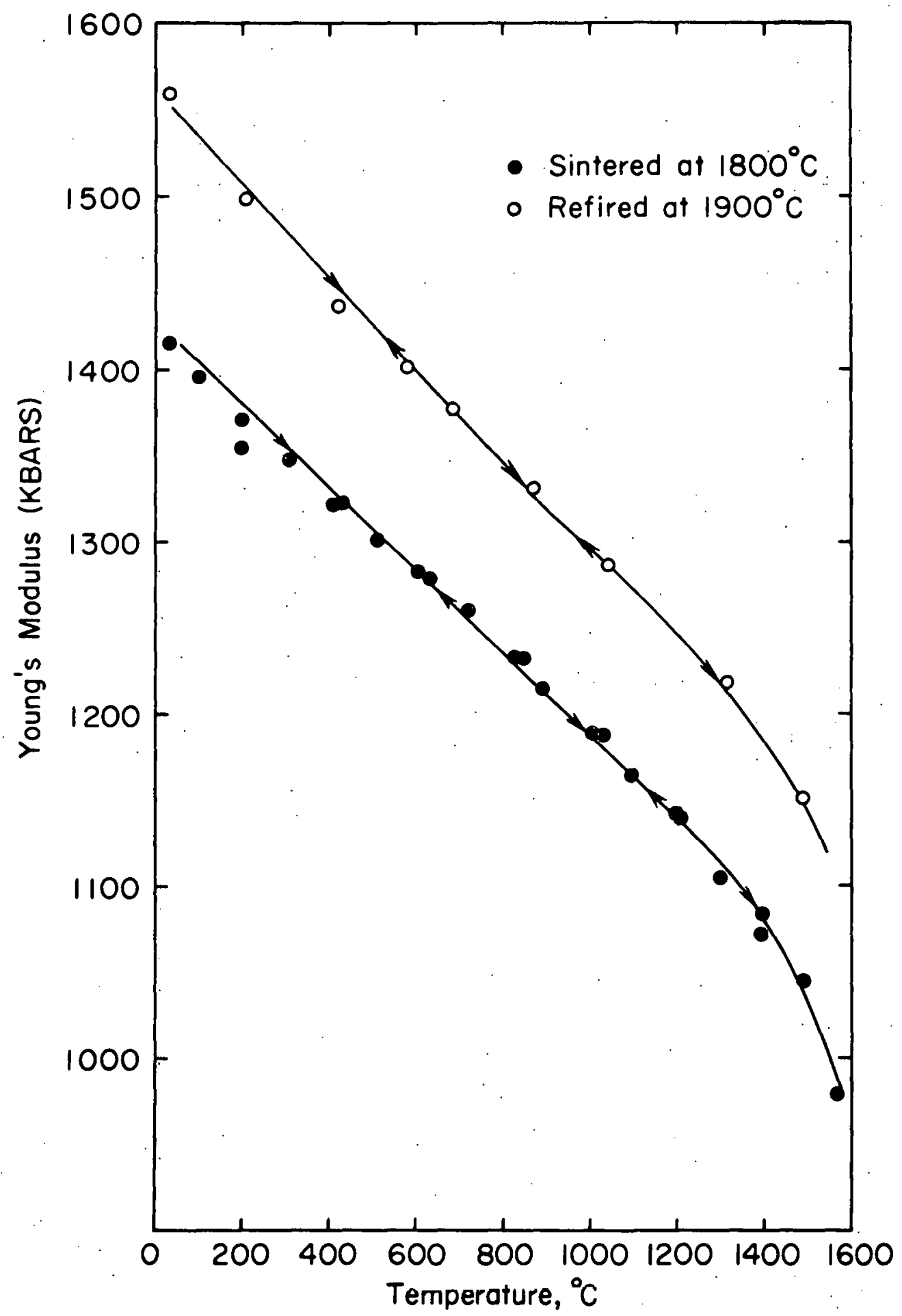

Figure 8. Elevated temperature Young's modulus on heating and cooling for sintered and refired $\mathrm{Eu}_{2} \mathrm{O}_{3}$ with $10.0 \mathrm{a} / 0 \mathrm{Ta}$ cation substitution 


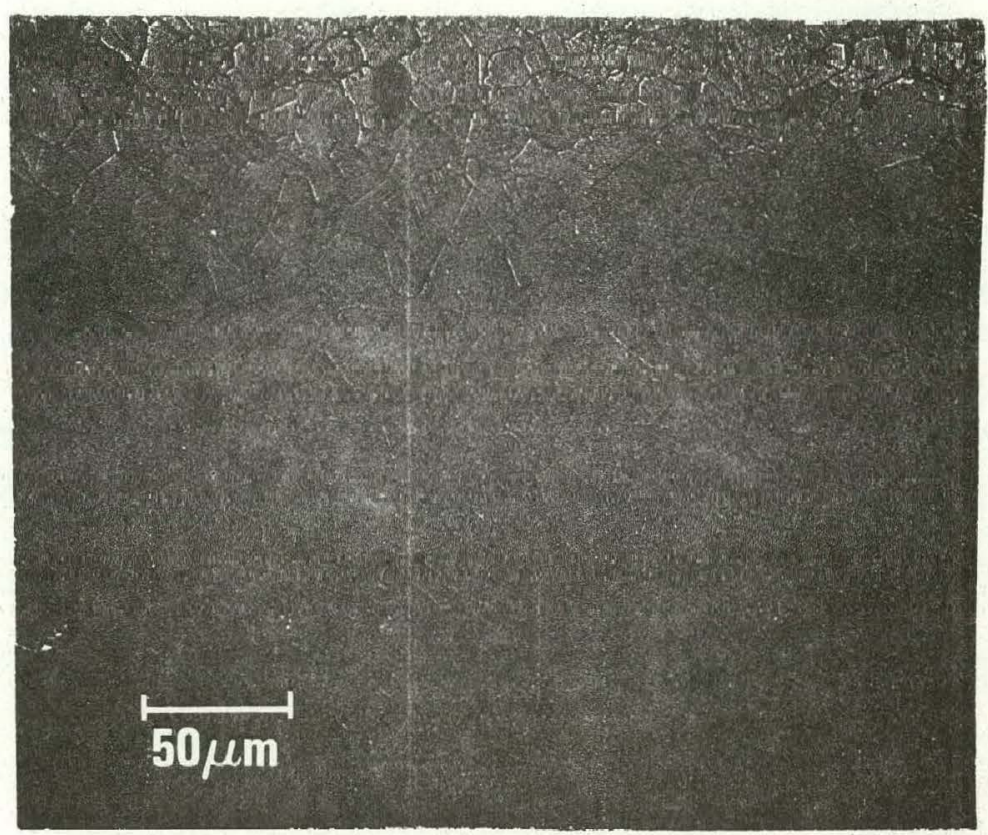

Figure 9a. Photomicrograph of a polished section of $\mathrm{Eu}_{2} \mathrm{O}_{3}$ with 0.50 a/o Ta cation substitution sintered at $1800^{\circ} \mathrm{C}$

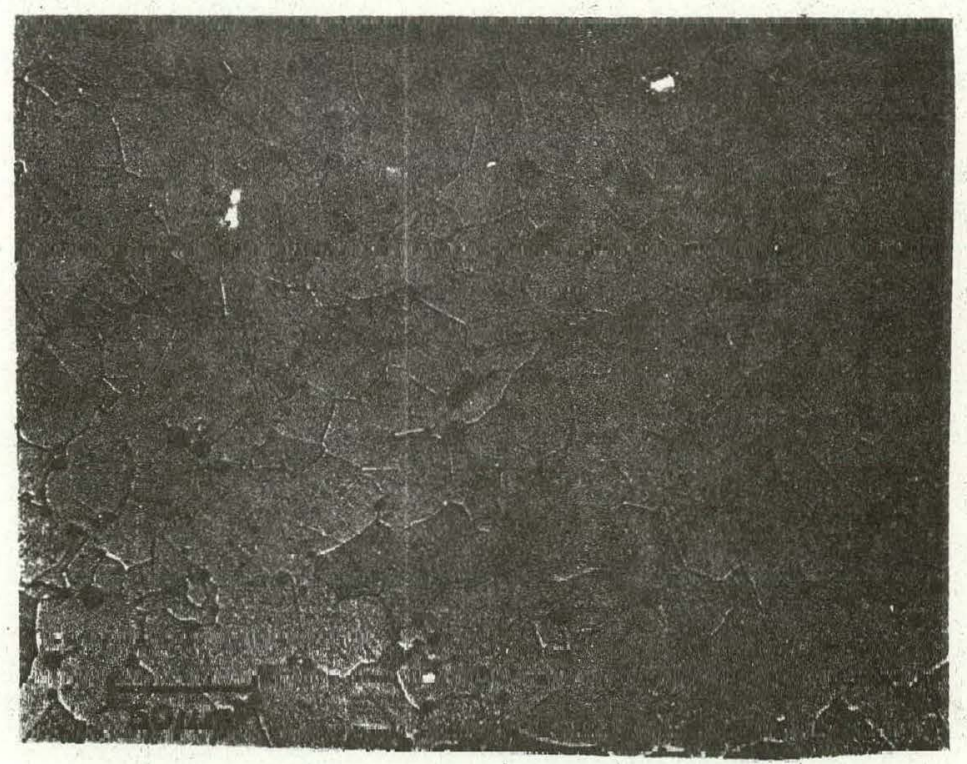

Figure 9b. Photomicrograph of a polished section of $\mathrm{Eu}_{2} \mathrm{O}_{3}$ with 0.50 a/o Ta cation substitution sintered at $1900^{\circ} \mathrm{C}$ 


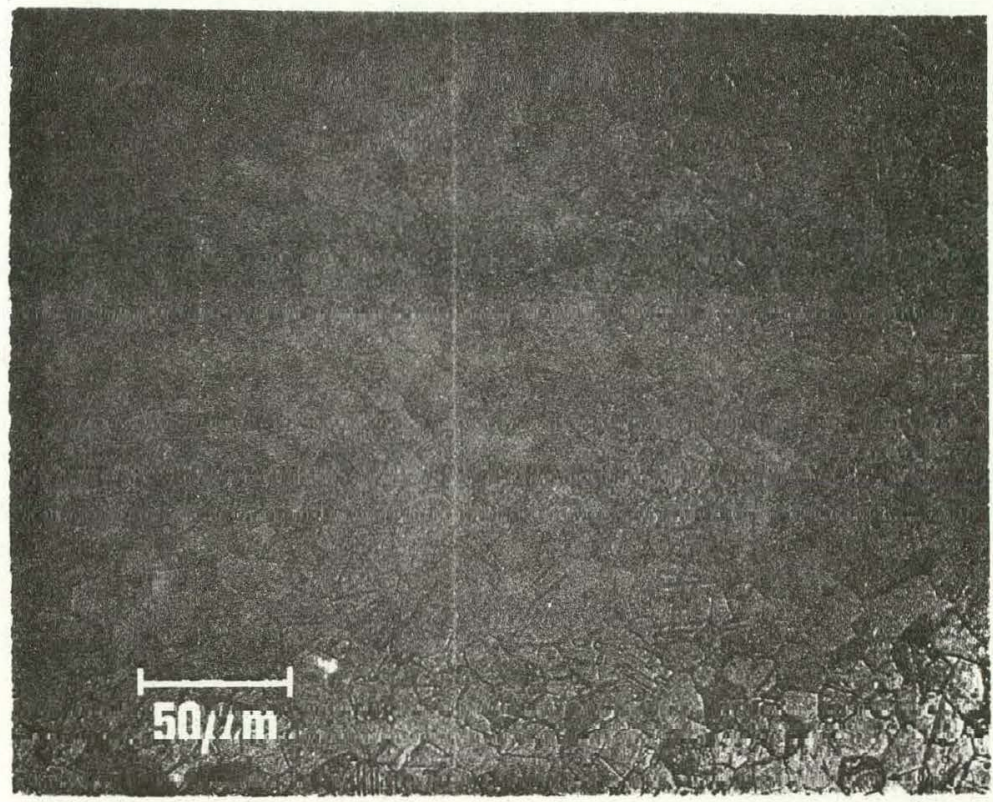

Figure 10a. Photomicrograph of a polished section of $\mathrm{Eu}_{2} \mathrm{O}_{3}$ with 1.0 a/o Ta cations substitution sintered at $1800^{\circ} \mathrm{C}$

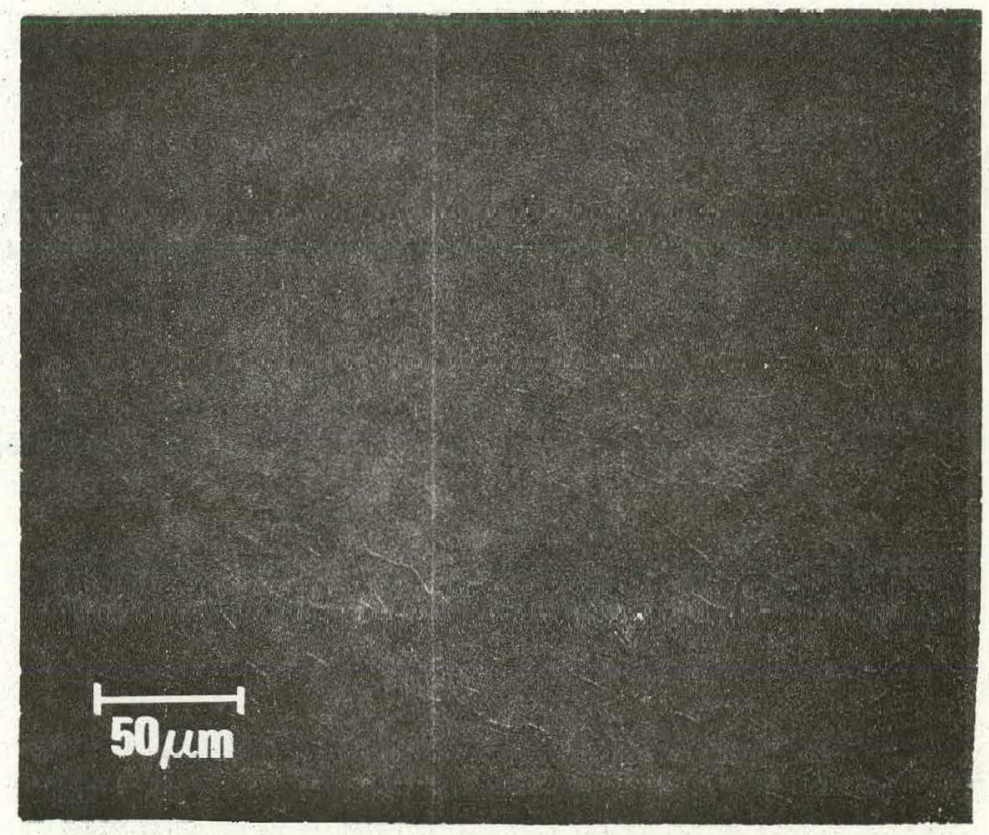

Fisure 10b. Fhotomicrograph of a polished section of $\mathrm{Eu}_{2} \mathrm{O}_{3}$ with 1.0 a/o Ta cation substitution refired at $1900^{\circ} \mathrm{C}$ 


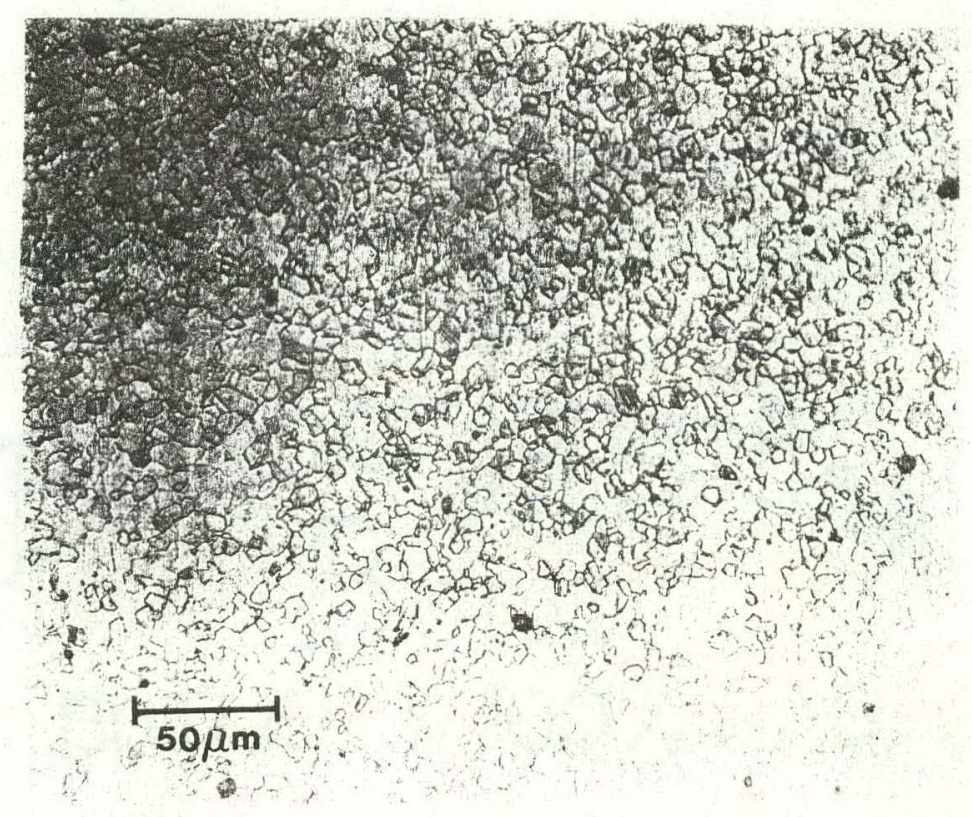

Figure 11a. Photomicrograph of a polished section of $\mathrm{Eu}_{2} \mathrm{O}_{3}$ with 1.5 a/o Ta cation substitution sintered at $1800^{\circ} \mathrm{C}$

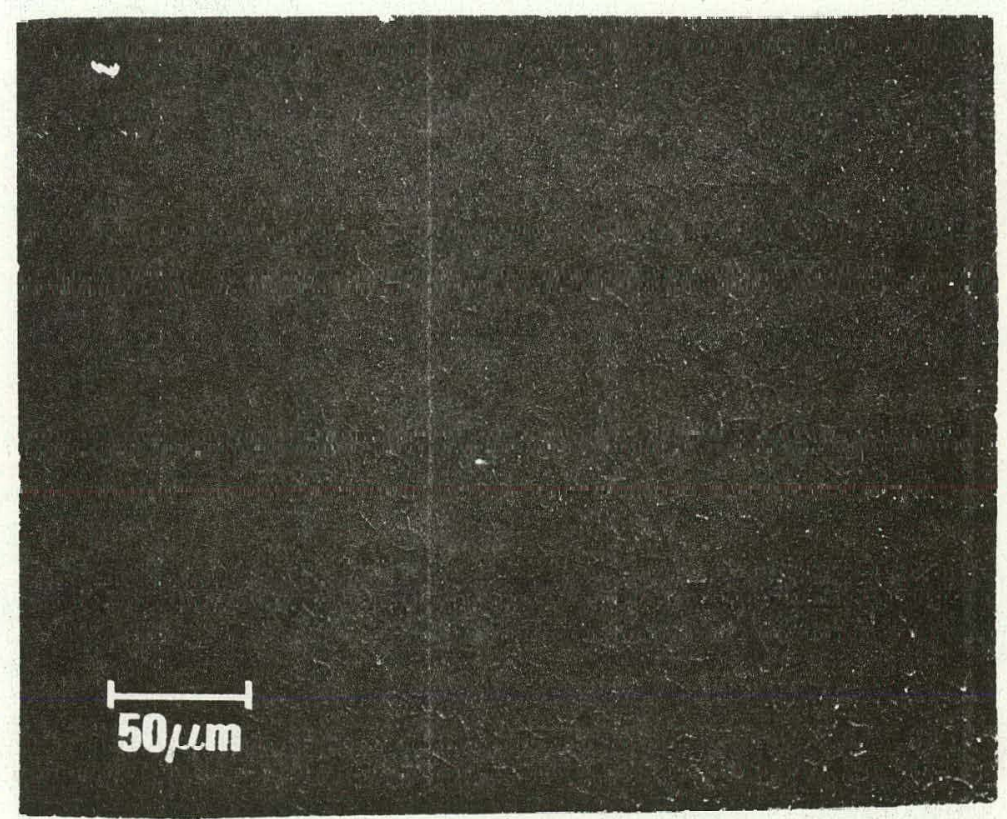

Fisure 11b. Photomicrograph of a polished section of $\mathrm{Eu}_{2} \mathrm{O}_{3}$ with 1.5 a/o Ta cation substitution refired at $1900^{\circ} \mathrm{C}$ 


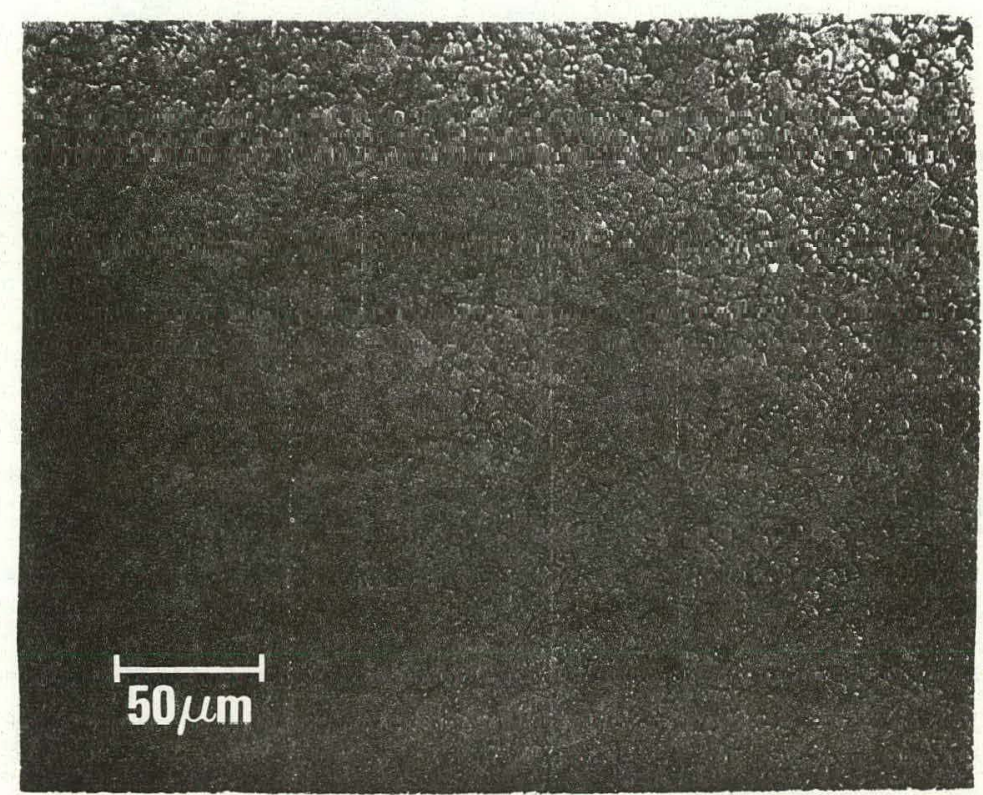

Figure 12. Photomicrograph of a polished section of $\mathrm{Eu}_{2} \mathrm{O}_{3}$ with 2.0 a/o Ta cation substitution sintered at $1800^{\circ} \mathrm{C}$ 


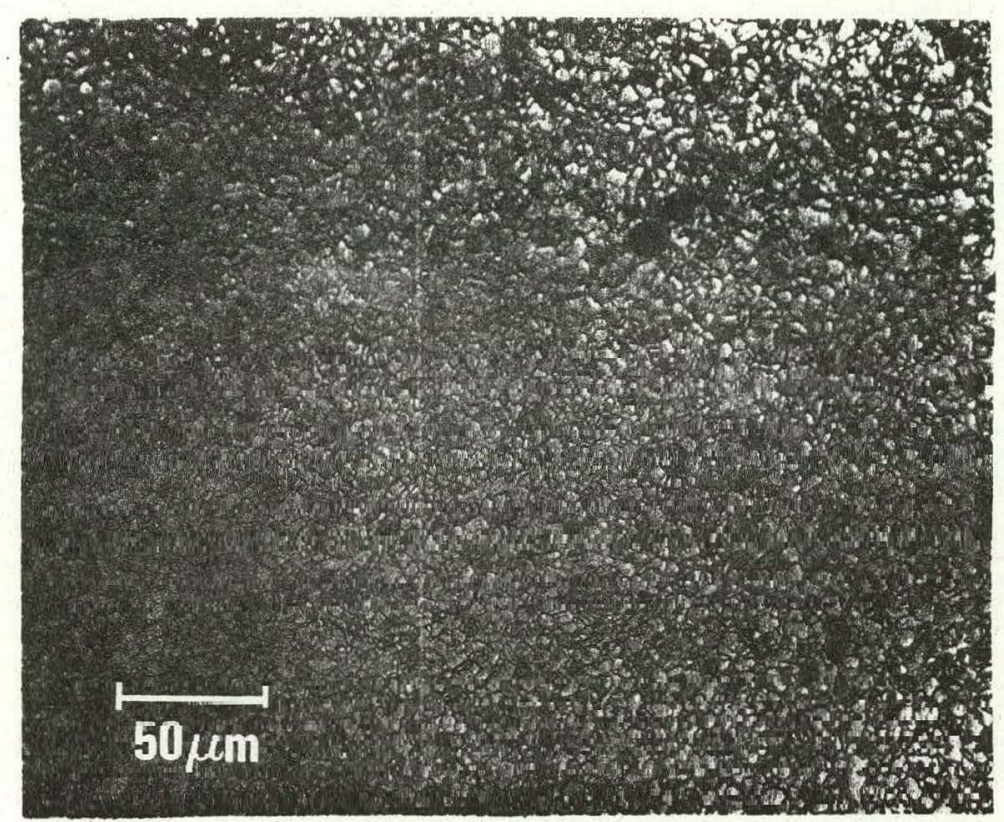

Figure 13a. Photomicrograph of a polished section of $\mathrm{Eu}_{2} \mathrm{O}_{3}$ with 4.0 a/o Ta cation substitution sintered at $1800^{\circ} \mathrm{C}$

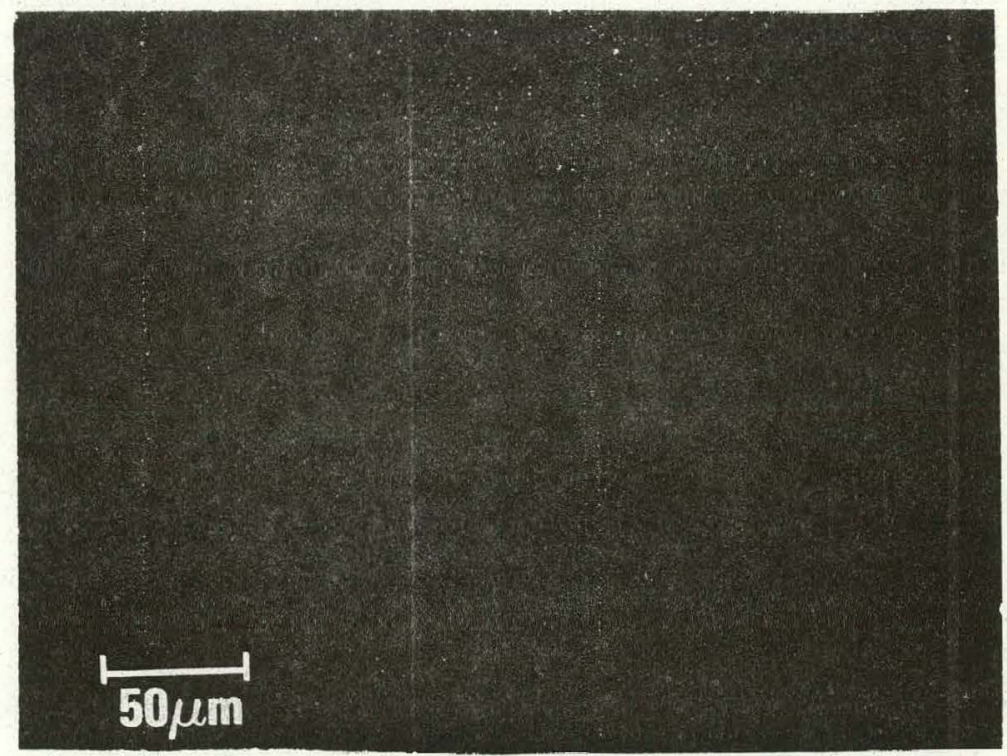

Figure 15b. Photomicrograph of a polished section of $\mathrm{Eu}_{2} \mathrm{O}_{3}$ with 4.0 a/o Ta cation substitution refired at $1900^{\circ} \mathrm{C}$ 


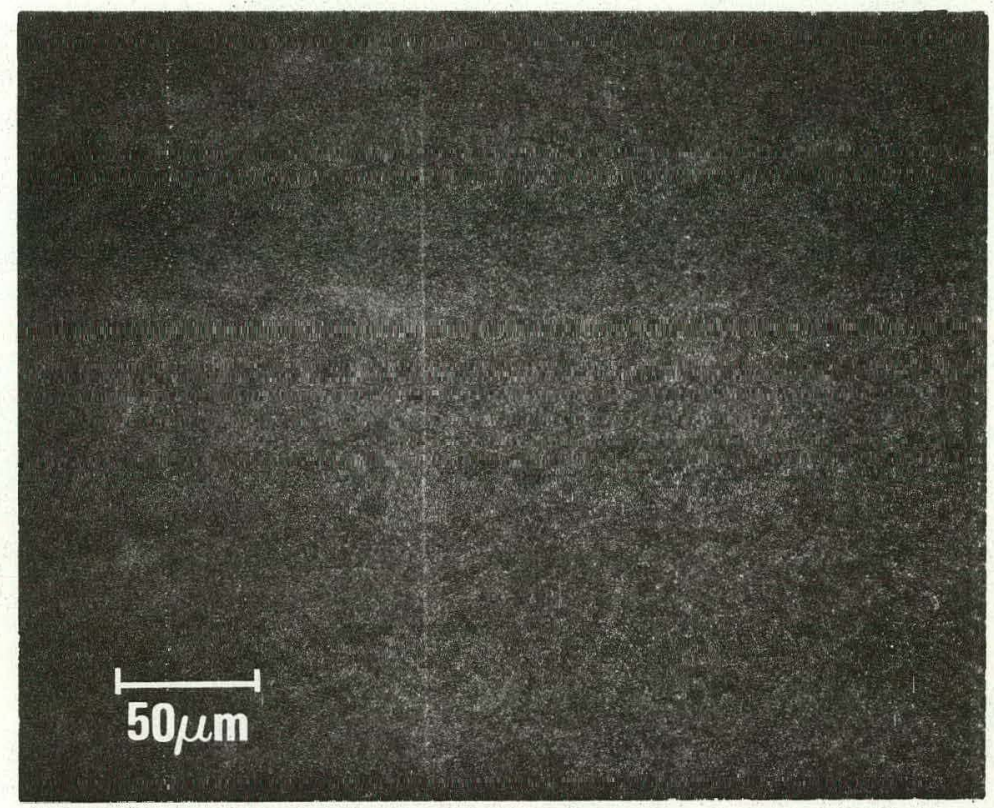

Figure 14a, Photomicrograph of a polished section of $\mathrm{Eu}_{2} \mathrm{O}_{3}$ with 6.0 a/o Ta cation substitution sintered at $1800^{\circ} \mathrm{C}$

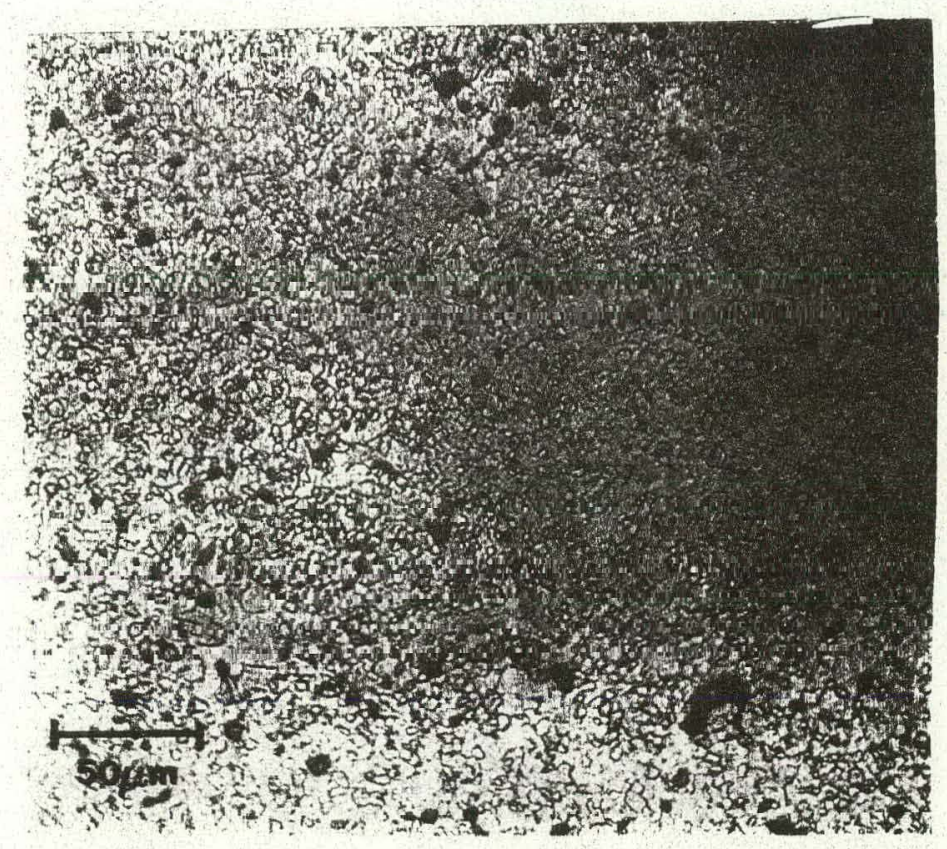

Figure 14b. Photomicrograph of a polished section of $\mathrm{Eu}_{2} \mathrm{O}_{3}$ with 6.0 a/0 Ta cation substitution refired at $1900^{\circ} \mathrm{C}$ 


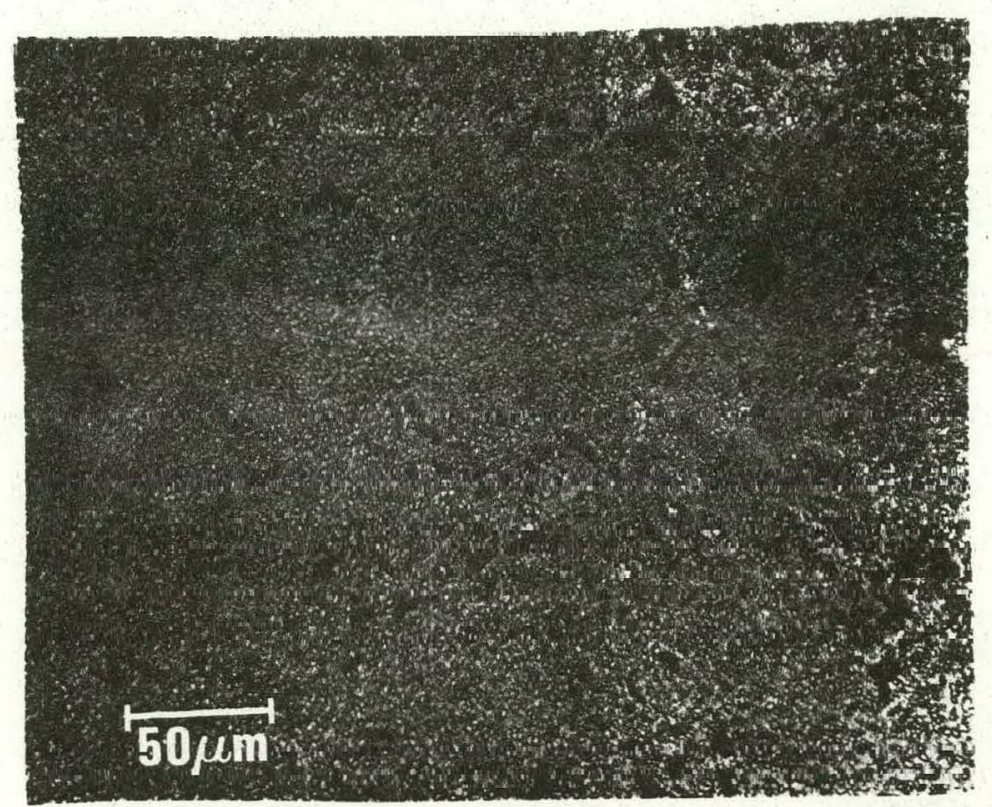

Figure 15a. Photomicrograph of a polished section of $\mathrm{Eu}_{2} \mathrm{O}_{3}$ with 10.0 a/o Ta cation substitution sintered at $1800^{\circ} \mathrm{C}$

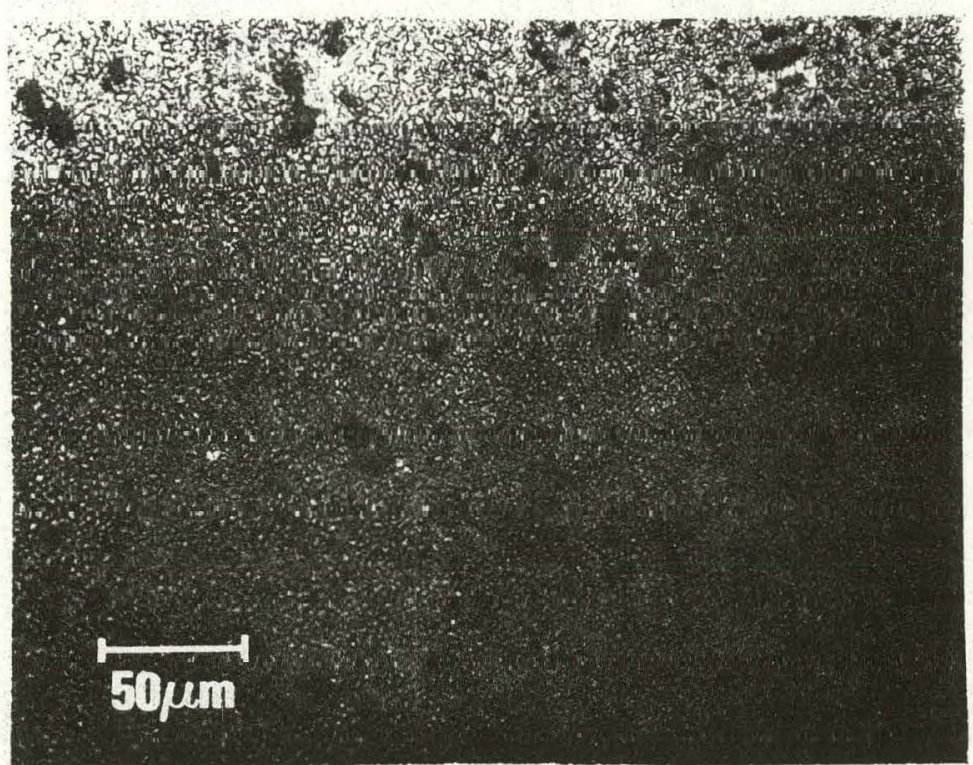

Figure 15b. Photomicrograph of a polished section of $\mathrm{Eu}_{2} \mathrm{O}_{3}$ with $10.0 \mathrm{a} / 0^{\mathrm{Ta}}$ cation substitution refired at $1900^{\circ} \mathrm{C}$ 
microcracked more extensively because of the large loop size when compared to the fired specimen!s loop size in Figures 2 , 3, and 4. These specimen's Young's modulus behaved in a similar manner except at $900^{\circ} \mathrm{C}$, the slope, $\mathrm{dE} / \mathrm{dT}$, did not become positive. The fired and refired specimens in Figures 2, 3 , and 4 had a rapidly decreasing modulus with increasing temperature above approximately $1300^{\circ} \mathrm{C}$. Suchomel and Hunter (4) found a similar decrease in modulus for the $\mathrm{HfO}_{2}-\mathrm{Eu}_{2} \mathrm{O}_{3}$ compositions, as did $\mathrm{Ke} \mathrm{(42)} \mathrm{and} \mathrm{Chang} \mathrm{(43).} \mathrm{for} \mathrm{other} \mathrm{materials}$ and attributed it to grain boundary sliding. It was assumed that grain boundary sliding was responsible for the rapid modulus decrease here. Specimens exhibited a near linear Young's modulus relation with temperature on cooling to approximately $1150^{\circ} \mathrm{C}$. The return to anomalous behavior below this temperature was assumed to be a result of microcrack formation. Grain sizes decreased with each consecutive addition of $\mathrm{Ta}$ as illustrated in the photomicrographs in Figures $9 \mathrm{a}$, 10a, and 11a. The decrease in grain size coincides with the decrease in loop size, leading to the assumption that as grain size decreases the amount of microstress relaxation by microcracking decreases while the relaxation by creep mechanisms increases. The microstresses associated with large grain sizes were relieved by microcrack formation and resulted in anomalous behavior on thermal cycling and abnormally low room temperature elastic behavior. 
The $0.5,1.0,1.5$, and 4.0 a/o Ta refired specimens also exhibited anomalous behavior as indicated by Figures 2, 3, 4, and 6. The size of the hysteresis loop is larger than the initially fired specimen loops for the respective compositions and could be described by a greater density of microcracking, a result of increased grain sizes. The loops do decrease in size as the Ta additions were increased, comparable to the behavior exhibited by the initially fired anomalously behaving specimens. Grain growth was once again suppressed with increasing $\mathrm{Ta}$ additions as indicated by the photomicrographs in Figures $9 b, 10 b, 11 b$ and $13 b$, and the decreasing grain size assumed to be responsible for decreasing loop size. The features present in the loops were similar to the loops for the initially fired specimens whose explanation was assumed valid for the refired specimens.

The transition region between linear and anomalous elastic-temperature relations was found to be at the 2.0 and 4.0 a/o Ta additions levels as illustrated in Figures 5 and 6 . The 2.0 and 4.0 a/o Ta initially fired specimens show a linear relation between elastic modulus and temperature, while the 4.0 a/o Ta refired specimen returns to anomalous elastic behavior. For this observed transition to occur, the mode of relaxation was assumed to shift from predominantly microcrack stress relaxation (hysteresis 10op) to a creep relaxation mechanism (1inear modulus temperature relation). Examination 
of the grain sizes for these specimens in Figures 12a, 13a, and $13 \mathrm{~b}$ provides a critical grain size region between $13.4 \mu \mathrm{m}$ for the initially fired 2.0 a/o Ta specimen (Iinear Young's modulus temperature relation) and $15.5 \mu \mathrm{m}$ for the refired 4.0 a/o Ta specimen (hysteresis 10op). The change in relaxation mechanism from microcracking to creep is supported by investigations by Heuer et al. (44) who have postulated that grain size inversely affects the degree of grain boundary sliding, hence the smaller the grain size, the greater the degree of grain boundary sliding, which is a creep mechanism.

The 6.0 and $10.0 \mathrm{a} / 0 \mathrm{Ta}$ fired and refired specimens were assumed to have completed the transition from predominant relaxation by microcracking to creep relaxation of the thermal expansion microstresses as illustrated by the linear modulustemperature relation found in Figures 7 and 8 . The grain growth was inhibited by the 6.0 and $10.0 \mathrm{a} / \mathrm{O} \mathrm{Ta}$ additions to such an extent that the grain sizes were below $10 \mu \mathrm{m}$ (Figures $14 \mathrm{a}, \mathrm{b}$ and $15 \mathrm{a}, \mathrm{b})$, lower than the critical region found to be between 14 and $15 \mu \mathrm{m}$. Refiring of the specimens did not cause a departure from linearity. The only remaining feature of the original hysteresis loop was the rapid decrease in modulus at approximately $1400^{\circ} \mathrm{C}$, assumed to be the result of grain boundary sliding.

When physical dimensions permitted, the shear modulus was determined for each specimen. In Figure 16 , the $10.0 \mathrm{a} / 0$ and 


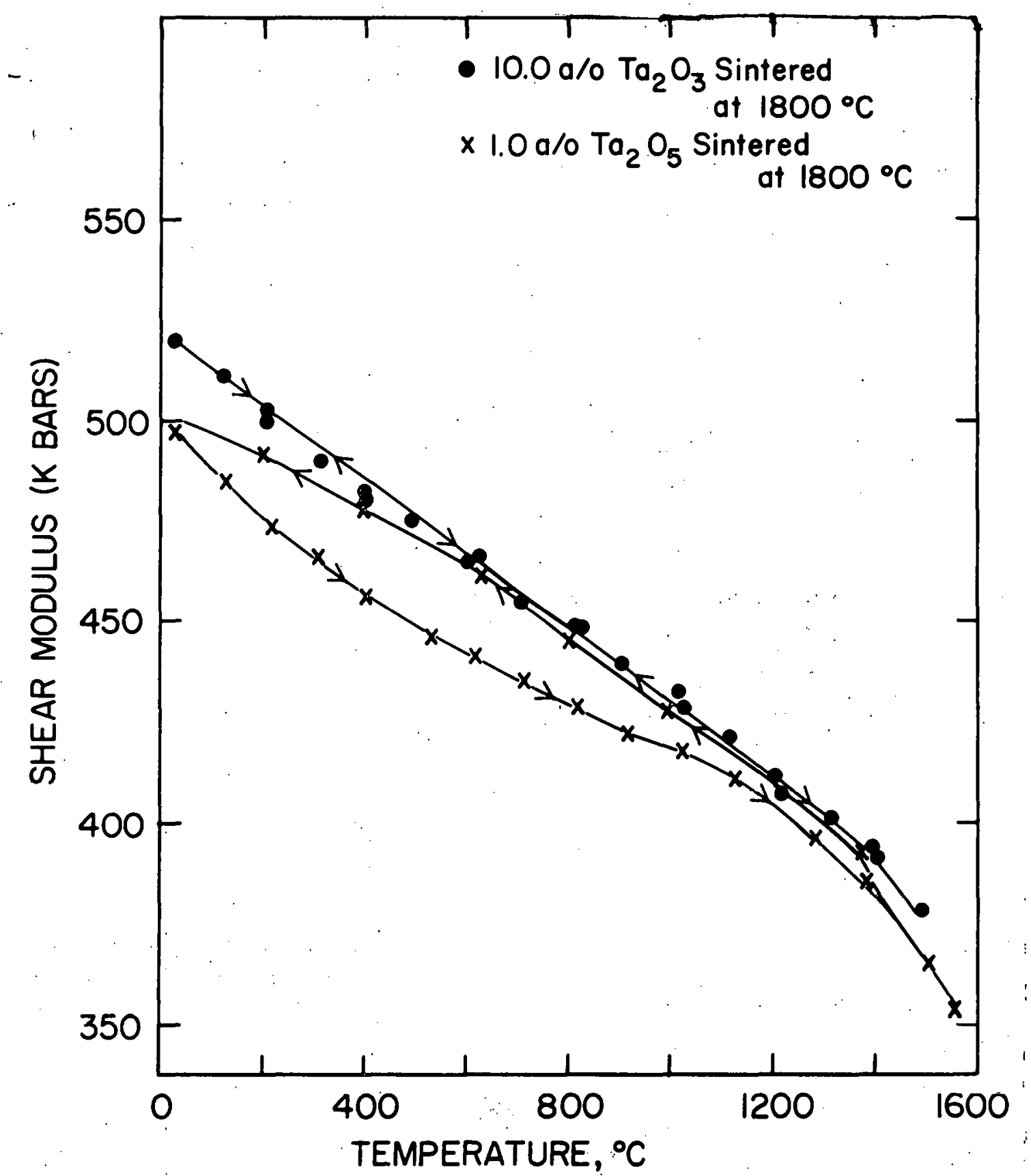

Figure 16. Elevated temperature shear modulus on heating and cooling of two $\mathrm{Ta}_{2} \mathrm{O}_{5}$ doped $\mathrm{Eu}_{2} \mathrm{O}_{3}$ specimens 
1.0 a/o Ta initially fired specimen's shear moduli are plotted relative to temperature. The larger grain size $1.0 \mathrm{a} / 0 \mathrm{Ta}$ $(31.5 \mu \mathrm{m})$ exhibited hysteresis while the smaller grain size $10.0 \mathrm{a} / 0 \mathrm{Ta}(7.4 \mathrm{\mu m})$ exhibited a linear shear modulus-temperature relation. The hysteresis loop size decreased and became linear as the grain size decreased in much the same fashion that the Young's modulus loop size decreased. The same relation was found for the refired specimens. This behavior is in agreement with investigations done by Suchome1 and Hunter (4) and Dole and Hunter ( 7 ), who found that the shear modulus was equally affected by a critical grain size-microcrack elastic behavior as was Young's modulus.

When both Young's modulus and shear modulus were available, Poisson's ratio, $\mu$, was calculated; however, no conclusive evidence was found to indicate a direct relation between $\mu$ and temperature. It did appear that where data were available, $\mu$, increased as temperature increased.

\section{Microstructural Effects on Internal Friction}

Internal friction of a specimen is dependent on porosity, composition, grain size, and sample integrity. Internal friction of each fired and refired specimen were calculated at room temperature to produce another discriminating parameter for microcrack identification.

Porosity

The specimen's internal friction, $Q_{S}^{-1}$, was first related 
to porosity, which can be represented by Marlowe's (26) equation

$$
\mathrm{Q}_{\mathrm{S}}^{-1}=a \mathrm{P}^{\mathrm{b}}
$$

where $a$ and $b$ are experimentally determined constants, and

$P$ is the volume fraction porosity.

Several investigators have found that $b$ is dependent on the particular material (45). Since many of the initially fired and refired specimens were of approximately the same density, implying the same volume fraction porosity, the effects on internal friction were assumed to be the same for all specimens.

Composition

The second parameter, composition, caused an abnormal behavior as illustrated in Figure 17. Several investigators have found that additions of a second component to a material will increase the internal friction in proportion to the addition $(46,47)$. In this case as the additions of $\mathrm{Ta}$ increases from $0.5 \mathrm{a} / 0$ to $10.0 \mathrm{a} / 0 \mathrm{Ta}$, the internal friction of the fired and refired specimens decreases contradicting the generally accepted theory. Assuming that compositional effects are not responsible for the behavior, another parameter must be the contributing factor.

Average grain size

Average grain size was related to the specimen internal friction values for fired and refired materials. Internal 


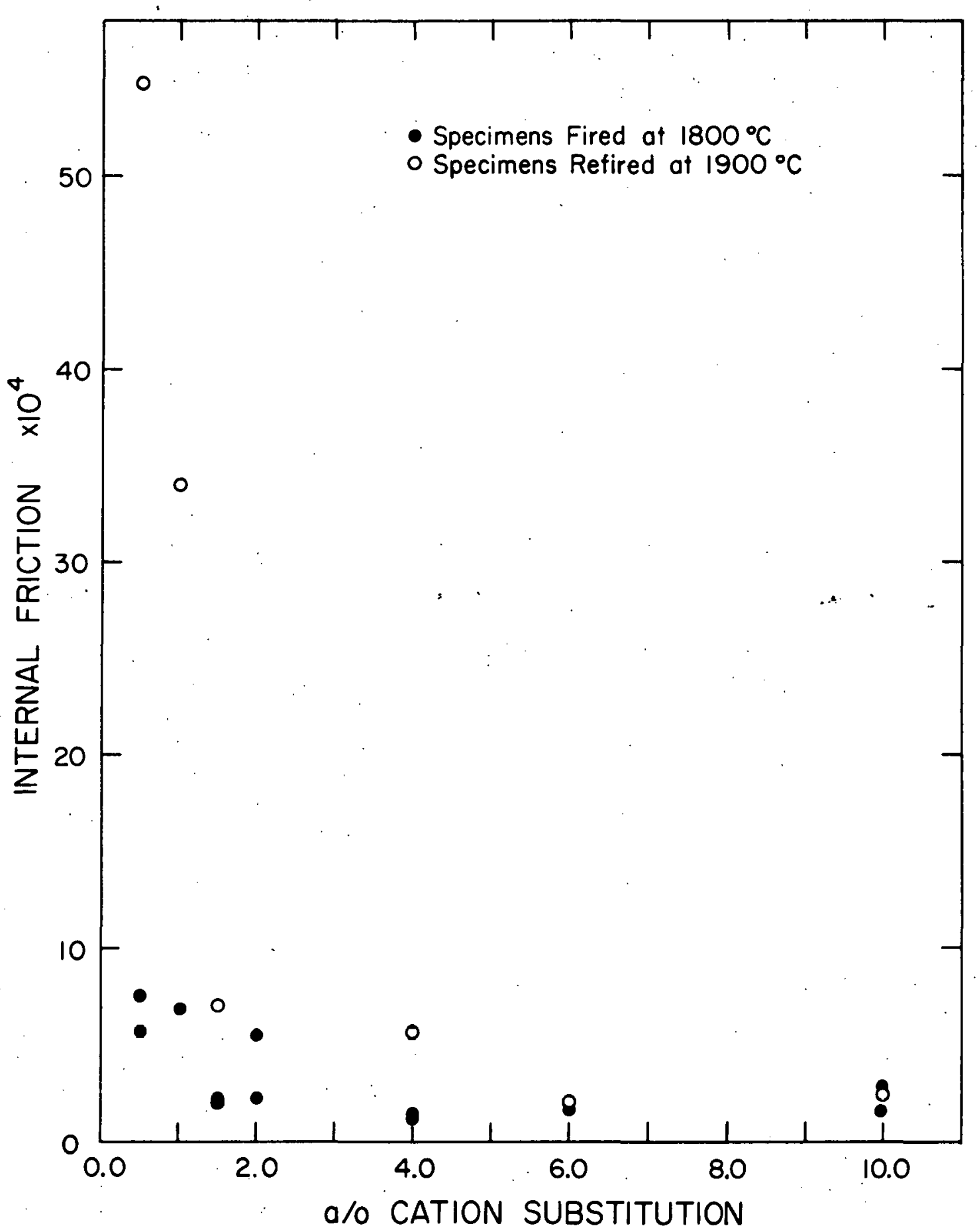

Figure 17. Internal friction of various. $\mathrm{Ta}_{2} \mathrm{O}_{5}$ doped $\mathrm{Eu}_{2} \mathrm{O}_{3}$ compositions fired at $1800^{\circ} \mathrm{C}$ and refired at $1900^{\circ} \mathrm{C}$ 
friction values should be directly proportional to grain boundary area or inversely proportional to grain size (22). However, in this case, the large grained fired and refired specimens exhibited the largest internal friction values. As the grain size of the specimens decreased, the internal friction decreased also, contradicting the above theory. This anomalous internal friction behavior with grain size is illustrated in Figure 18. From these results, it was assumed that grain boundaries were not the controlling factor for the observed internal friction values. Sample integrity

Since porosity, composition, and grain size effects cannot account for the abnormal internal friction behavior, the sample integrity must be responsible. Elasticity measurements have already indicated that the material may be microcracked to various degrees depending on the grain size. Two recent investigations $(21,12)$ have also found internal frictiongrain size relation abnormalities for $\mathrm{HfO}_{2}$ and several pseudobrookites, assuming that microcracking was the predominant contributor to the internal frictions observed. They found that the grain size decrease coincided with decreasing internal friction values, much the same as this investigation did for $\mathrm{Eu}_{2} \mathrm{O}_{3}$ as illustrated in Figure 18. Solid symbols in Figure 18 are representative of those samples exhibiting anomalous elastic behavior, believed to be caused by micro- 


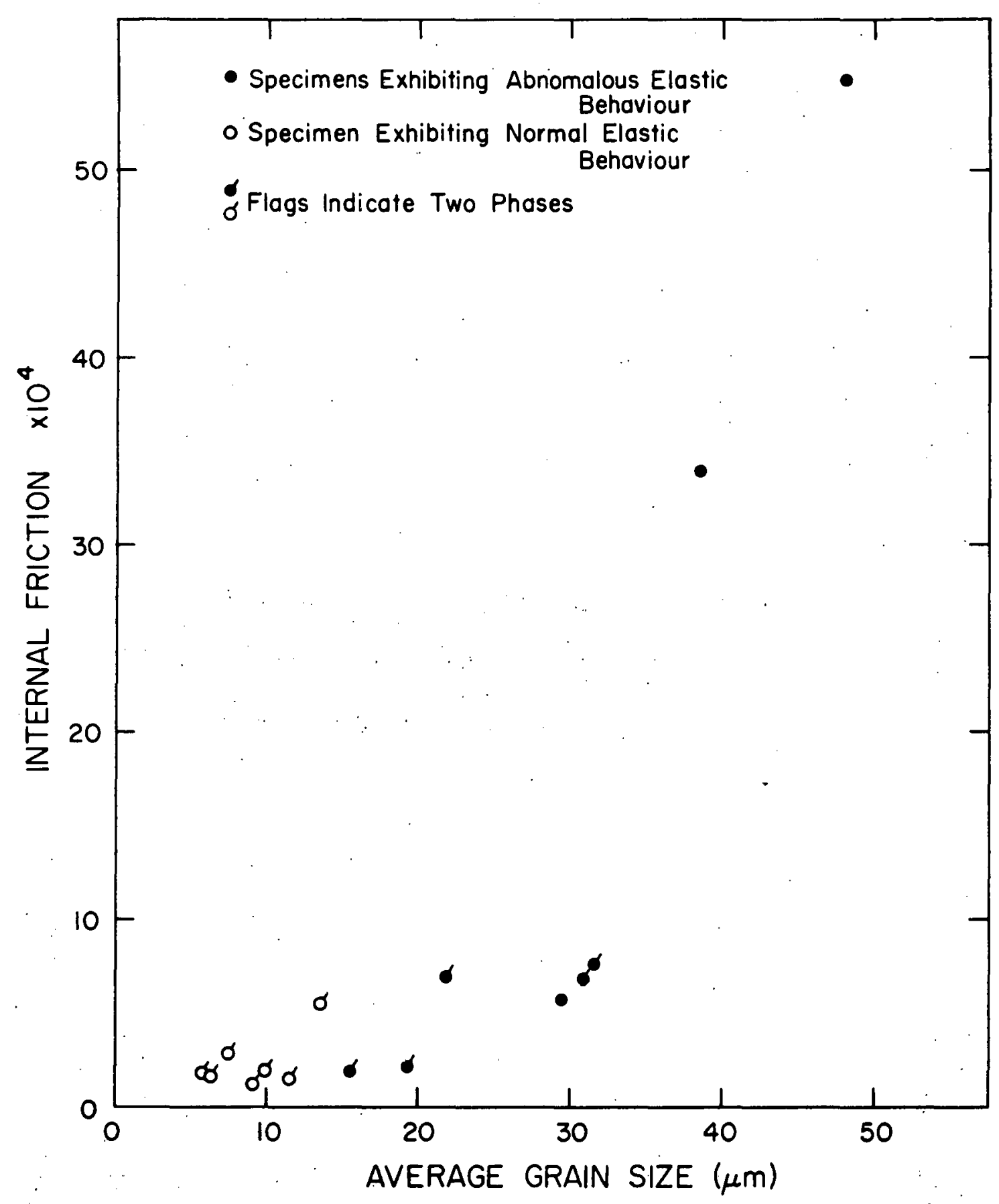

Figure 18. Internal friction for various grain sizes of $\mathrm{Ta}_{2} \mathrm{O}_{5}$ doped $\mathrm{Eu}_{2} \mathrm{O}_{3}$ compositions 
cracks. It was assumed that the larger density of microcracks in the large grain sized specimens caused the abnormally high internal friction values and masked the effects that porosity, grain size and composition had on the internal friction values. $\mathrm{Y}_{2} \mathrm{O}_{3}$, another rare earth oxide which does not exhibit elastic behavior indicative of microcracking, had internal friction values of $0.89 \times 10^{-4}$ (26). For comparable grain sized $\mathrm{Ta}_{2} \mathrm{O}_{5} \mathrm{Eu}_{2} \mathrm{O}_{3}$ specimens, values were above $3.0 \times 10^{-4}$ and increased with increasing grain size, a result of a higher density of microcracks.

High Temperature Internal Friction

Large grain sized fired and refired $0.5,1.0$, and $1.5 \mathrm{a} / \mathrm{o}$ Ta exhibited high internal friction values at elevated temperatures. A11 of the specimens also exhibited a rapid increase in internal friction above $1400^{\circ} \mathrm{C}$, coincident with the rapid decrease in modulus: This was assumed to be the result of grain boundary sliding. Smaller grain sized, fired and refired specimens of $2.0,4.0,6.0$, and 10.0 a/o $\mathrm{Ta}$ composition, had much lower internal friction values at elevated temperature, but still contained the rapid increase in internal friction above $1400^{\circ} \mathrm{C}$. The internal friction values at elevated temperature progressively declined with grain size, similar to the elastic modulus behavior described earlier. Figure 19, the 1.0 a/o Ta fired and refired specimens, is representative of the large grained specimens elevated 


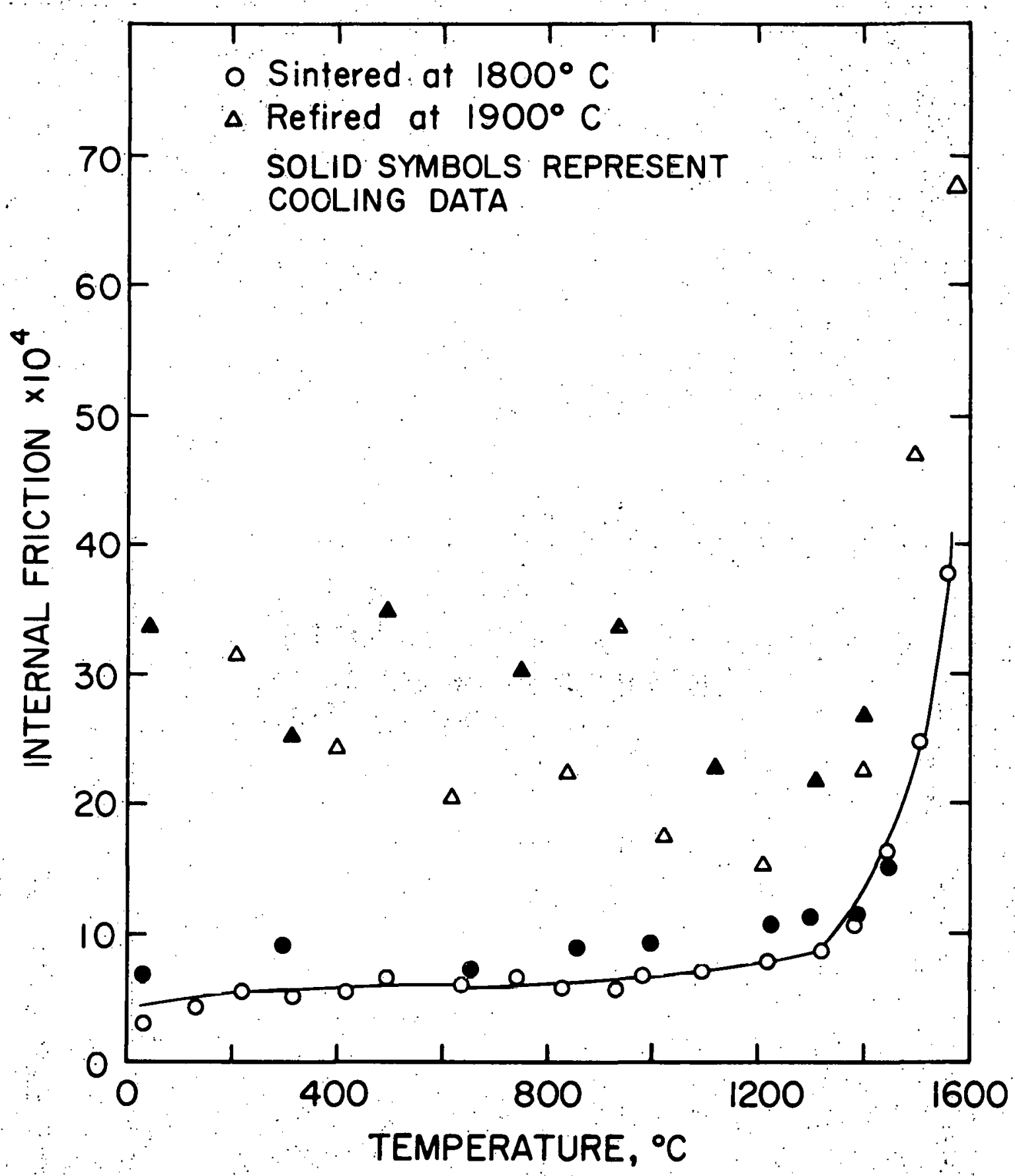

Figure 19. Elevated temperature internal friction of $\mathrm{Eu}_{2} \mathrm{O}_{3}$ with 1,0 a/0 Ta cation substitution sintered and refired specimens. 
temperature internal friction behavior. The refired specimen (38.4 $\mu \mathrm{m})$ had a larger internal friction than the fired (30.8 m) specimen. It was assumed that the higher values were the result of a greater density of microcracks in the larger grained specimen. Both specimens exhibited the rapid internal friction increase associated with grain boundary sliding.

Specimens with smaller grain size, illustrated by the 6.0 a/o Ta composition in Figure 20, had lower elevated temperature internal frictions. The rapid internal friction increase above $1400^{\circ} \mathrm{C}$ was still present and once again was assumed to be the result of grain boundary sliding. The smaller grain sized material was assumed to contain a lower density of microcracks. This was also indicated by the lower elevated temperature internal friction values found during thermal cycling. Scatter in the data made it impossible to draw any other conclusions.

Thermal Expansion Anisotropies of $\mathrm{Eu}_{2} \mathrm{O}_{3}$

In order to support the postulate that microcracking and anomalous elastic properties are directly related to grain size a study of the axial thermal expansions of monoclinic $\mathrm{Eu}_{2} \mathrm{O}_{3}$ were made and compared to the literature values for $\mathrm{Gd}_{2} \mathrm{O}_{3}$, a rare-earth oxide with similar elastic properties and structure in the non-microcracked form. The work of Ploetz et al. (31) has shown that $\mathrm{Eu}_{2} \mathrm{O}_{3}$ has more of a properisity for grain growth than $\mathrm{Gd}_{2} \mathrm{O}_{3}$, al though it is possible to induce a 


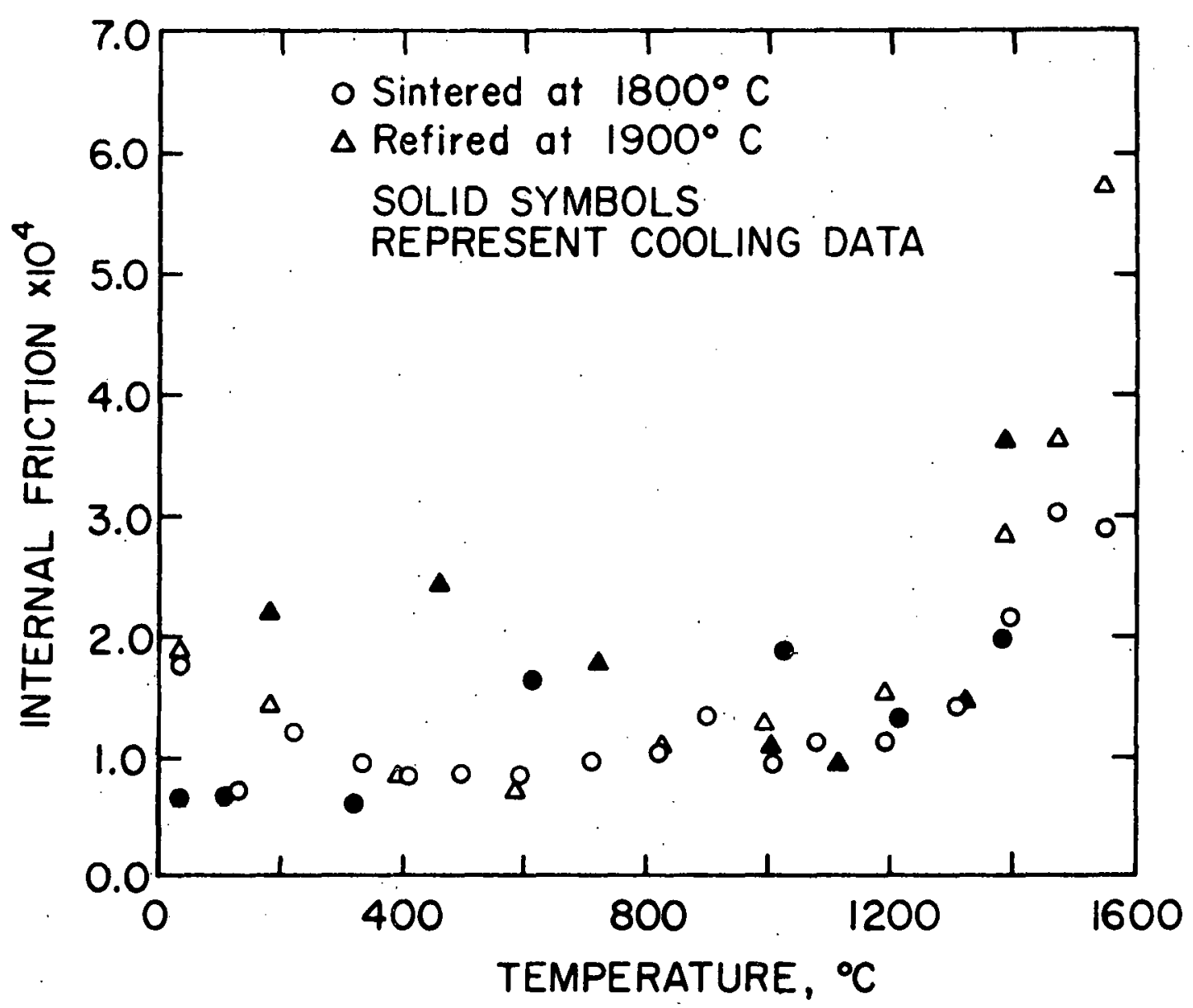

Figure 20. Elevated temperature internal friction of $\mathrm{Eu}_{2} \mathrm{O}_{3}$ with" $6.0 \mathrm{a} / 0$. Ta cation substitution sintered and refired specimens 
significant amount of grain growth in $\mathrm{Gd}_{2} \mathrm{O}_{3}$ by thermal treatment (7). The studies of Suchomel and Hunter (4) and Haglund and Hunter (14) show that the moduli of these two materials are very similar provided the grain size is small enough. Suchomel and Hunter (4) have shown that rapid grain growth in $\mathrm{Eu}_{2} \mathrm{O}_{3}$ during fabrication makes it easy to produce $\mathrm{Eu}_{2} \mathrm{O}_{3}$ with anomalous elastic properties. Haglund and Hunter (14) showed that $\mathrm{Gd}_{2} \mathrm{O}_{3}$ does not have such rapid grain growth during sintering and consequently does not have anomalously low elastic moduli. However, the later work of Dole and Hunter (7) showed that further heat treatment could induce grain growth and when the grain size was comparable to the coarsened $\mathrm{Eu}_{2} \mathrm{O}_{3}$, anomalous elastic properties resulted. Since the internal stresses for a given material are dependent upon the elastic properties and expansion anisotropies, the possibility exists that a larger thermal expansion anisotropy for $\mathrm{Eu}_{2} \mathrm{O}_{3}$ when compared to $\mathrm{Gd}_{2} \mathrm{O}_{3}$ thermal expansion anisotropy could result in easier microcracking in $\mathrm{Eu}_{2} \mathrm{O}_{3}$. By comparing the two thermal expansion anisotropies, it was possible to conclude that grain size was the controlling factor for microcracking. The temperature range chosen was between room temperature and $1000^{\circ} \mathrm{C}$, assuming that most of the microcrack formation occurred in this range.

Lattice constants for $\mathrm{Eu}_{2} \mathrm{O}_{3}$ were fit to an equation of the form 


$$
Y=k+\ell \Delta T+m \Delta T^{2}
$$

where $Y$ is the lattice parameter of interest,

$\mathrm{k}, \ell$, and $\mathrm{m}$ are experimentally derived constants, and

$\Delta \mathrm{T}$ is the difference in temperature $\mathrm{T}_{1}$ and $\mathrm{T}_{2} \cdot$

Figure 21 illustrates the lattice constants relation with temperature for monoclinic $\mathrm{Eu}_{2} \mathrm{O}_{3}$.

The average linear thermal expansion, $\alpha$, was derived from the equation

$$
\alpha=\frac{1}{3} \frac{\Delta V}{V_{0} \Delta T}
$$

where $\Delta \mathrm{V}$ is the volume change between temperatures $\mathrm{T}_{1}$ and $\mathrm{T}_{2}$ and $\Delta \mathrm{V}_{0}$ is the original volume at $\mathrm{T}_{1}$, by using the volume expansion data in Figure 21. This yielded a value of $11.09 \times 10^{-6}{ }^{\circ} \mathrm{C}^{-1}$ for monoclinic $\mathrm{Eu}_{2} \mathrm{O}_{3}$ using high temperature diffractometer techniques, $10 \%$ larger than Suchomel's dilatometer value of $9.9 \times 10^{-6}{ }^{\circ} \mathrm{C}^{-1}$ for polycrystalline monoclinic $\mathrm{Eu}_{2} \mathrm{O}_{3}$.

A thermal expansion coefficient was calculated for each crystallographic axis by application of the equation

$$
\alpha_{\mathrm{x}}=\frac{\Delta \mathrm{L}}{\mathrm{L}_{\mathrm{o}} \Delta \mathrm{T}}
$$

where $\alpha_{x}$ is the average linear coefficient of thermal expansion for a specific axis;

$\Delta \mathrm{L}$ is the change in length of the axis between $\mathrm{T}_{1}$ and $\mathrm{T}_{2}$, and

$L_{0}$ is the length of the axis at room temperature, 


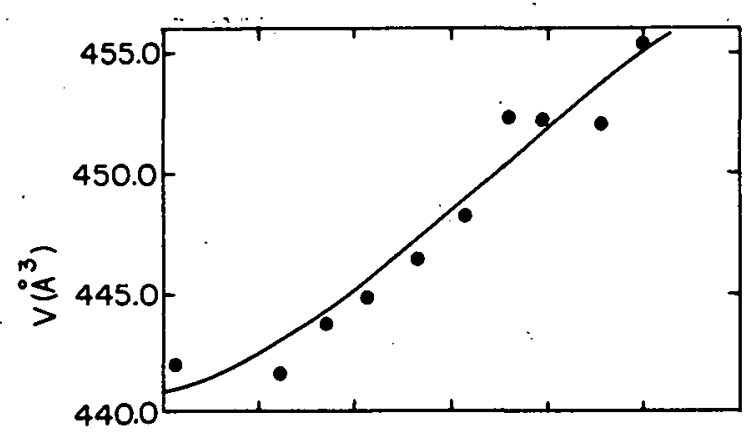

$V=440.8826+7.034 \times 10^{-3} \Delta T+7.46 \times 10^{-6} \Delta T^{2}$

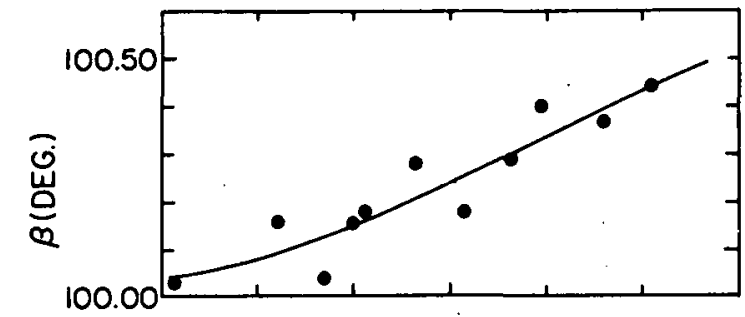

$\beta=100.8212+28.7 \times 10^{-5} \Delta T+12.0 \times 10^{-8} \Delta T^{2}$

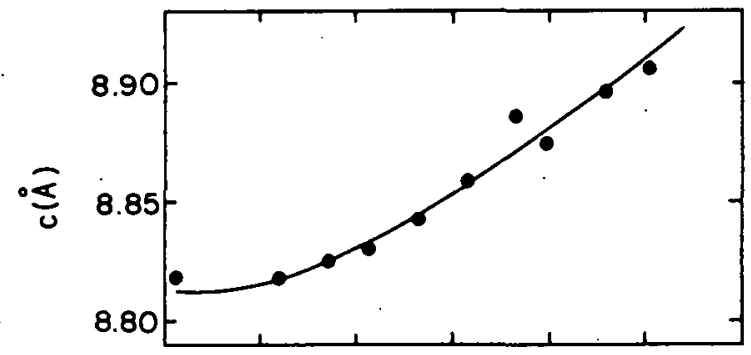

$c=8.8121+2.35 \times 10^{-5} \Delta T+7.0 \times 10^{-8} \Delta T^{2}$

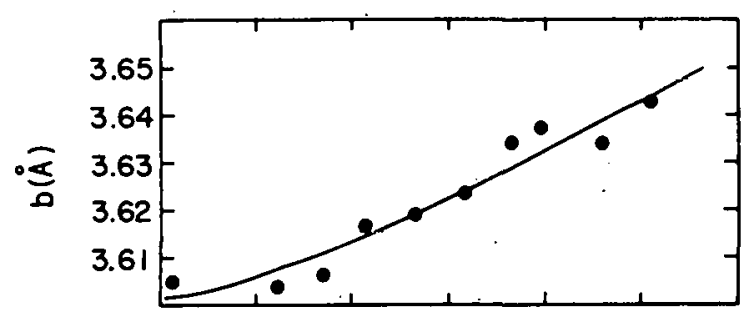

$b=3.6001+2.71 \times 10^{-5} \Delta T+1.0 \times 10^{-8} \Delta T^{2}$

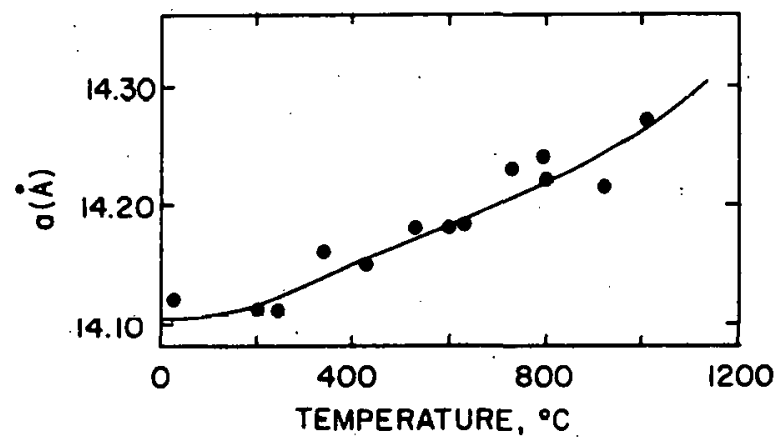

$0=14.1128+9.20 \times 10^{-5} \Delta T+5.0 \times 10^{-8} \Delta T^{2}$

Figure 21. Unit cell parameters from $25^{\circ} \mathrm{C}$ to $1000^{\circ} \mathrm{C}$ for monoclinic $\mathrm{Eu}_{2} \mathrm{O}_{3}$ 
The $\mathrm{Eu}_{2} \mathrm{O}_{3}$ axial thermal expansion coefficients, listed in Table 2 , were calculated to be $\alpha_{a}=11.04 \times 10^{-6 \circ} \mathrm{C}^{-1}, \alpha_{b}=$ $13.43 \times 10^{-6}{ }^{\circ} \mathrm{C}^{-1}$, and $\alpha_{c}=11.97 \times 10^{-6}{ }^{\circ} \mathrm{C}^{-1}$ for the crystal axes $a, b$, and c respectively. In a similar determination, Sawbridge and Waterman (6) found the expansion coefficients for monoclinic $\mathrm{Gd}_{2} \mathrm{O}_{3}$ to be $\alpha_{\mathrm{a}}=9.74 \times 10^{-6}{ }^{\circ} \mathrm{C}^{-1}, \alpha_{\mathrm{b}}=15.45 \mathrm{x}$ $10^{-6 \circ} \mathrm{C}^{-1}$, and $a_{c}=11.83 \times 10^{-60} \mathrm{C}^{-1}$, also isted in Table 2 . The data for $\mathrm{Eu}_{2} \mathrm{O}_{3}$ was generated from $x$-ray data between $30^{\circ}$ and $70^{\circ} 2 \theta$ while the $\mathrm{Gd}_{2} \mathrm{O}_{3}$ data were between $40^{\circ}$ and $144^{\circ} 2 \theta$. Even though the accuracy of the $\mathrm{Eu}_{2} \mathrm{O}_{3}$ data is somewhat questionable, the expansions seem to be reasonable. Both $\mathrm{Gd}_{2} \mathrm{O}_{3}$ and $\mathrm{Eu}_{2} \mathrm{O}_{3}$ have their maximum expansions along the $b$ axis and the minimum along the a axis.

The term, $\alpha_{\min } / \alpha_{\max }$, was designated as the degree of anisotropy, where $\alpha_{\min }$ is the minimum axial expansion coefficient and $\alpha_{\max }$ is the maximum expansion coefficient, and calculated for both $\mathrm{Gd}_{2} \mathrm{O}_{3}$ and $\mathrm{Eu}_{2} \mathrm{O}_{3}$. As the ratio $\alpha_{\min } / \alpha_{\max }$ decreases, the anisotropy increases. The values for $\mathrm{Gd}_{2} \mathrm{O}_{3}$ and $\mathrm{Eu}_{2} \mathrm{O}_{3}$ were calculated to be 0.631 and 0.822 respectively, indicating that the $\mathrm{Gd}_{2} \mathrm{O}_{3}$ was more anisotropic than $\mathrm{Eu}_{2} \mathrm{O}_{3}$. Easier microcracking in $\mathrm{Gd}_{2} \mathrm{O}_{3}$ should be the result, however, it has been experimentally shown that $\mathrm{Eu}_{2} \mathrm{O}_{3}$ is more susceptible to microcracking. The only compensating difference is europia's propensity for grain coarsening.

Anomalous behavior can also be explained by polymorphic 
Table 2. Axial thermal expansion values for $\mathrm{Gd}_{2} \mathrm{O}_{3}$ and $\mathrm{Eu}_{2} \mathrm{O}_{3}$ between room temperature and $1000^{\circ} \mathrm{C}$

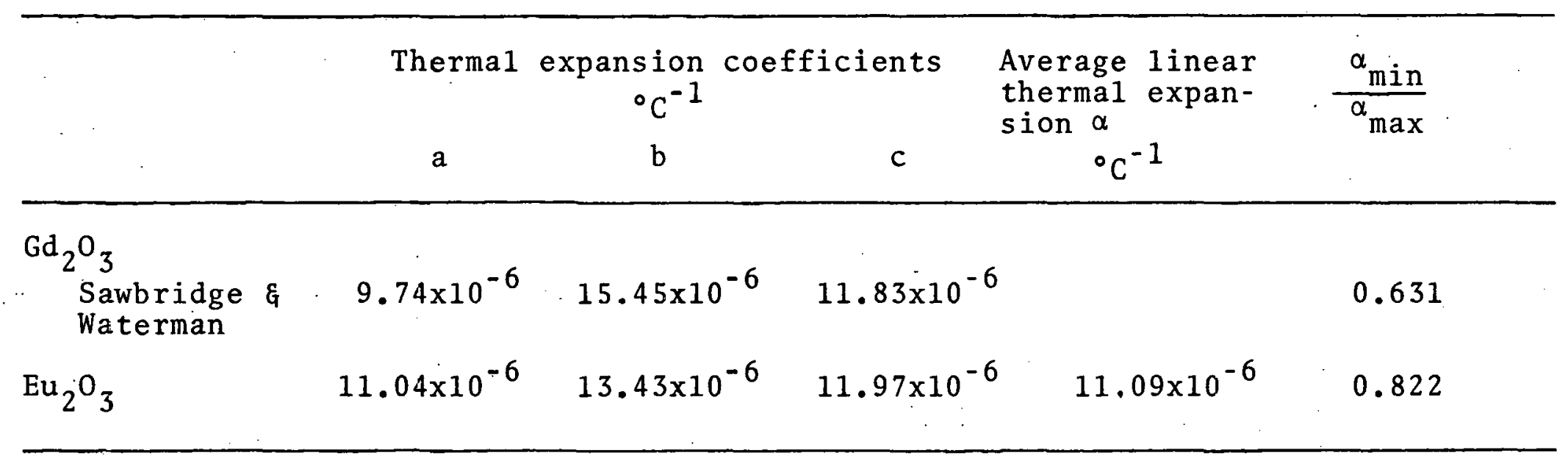


transformations, however, literature reveals that the cubicto-monoclinic transformation (48) is irreversible. The high temperature $x$-ray data from this investigation support this postulate since no second phase was precipitated out as the $\mathrm{Eu}_{2} \mathrm{O}_{3}$ was thermally cycled.

The lack of the monoclinic-to-cubic transformation and similarity in the axial thermal expansion coefficients to a $\mathrm{Eu}_{2} \mathrm{O}_{3}$ and $\mathrm{Gd}_{2} \mathrm{O}_{3}$ further support the postulate that grain coarsening associated with sintering of $\mathrm{Eu}_{2} \mathrm{O}_{3}$ is the controlling factor for microcrack-anomalous behavior relations. 


\section{CONCLUSIONS}

1. Large grain sized $\mathrm{Ta}_{2} \mathrm{O}_{5}-\mathrm{Eu}_{2} \mathrm{O}_{3}$ compositions exhibit anomalous elastic behavior. On heating and cooling, both Young's and shear moduli display hysteresis.

2. Increasing additions of $\mathrm{Ta}_{2} \mathrm{O}_{5}$ to $\mathrm{Eu}_{2} \mathrm{O}_{3}$ inhibit the grain growth and produce progressively smaller grain sized specimens .

3. Small grain sized $\mathrm{Ta}_{2} \mathrm{O}_{5}-\mathrm{Eu}_{2} \mathrm{O}_{3}$ sintered compositions exhibit normal elastic behavior during thermal cycling.

4. Room temperature internal friction values are directly related to grain size. This is the result of extensive microcracking in large grained specimens.

5. Elevated temperature internal friction values increase rapidly above $1300^{\circ} \mathrm{C}$ and are coincident with rapidly decreasing modulus values. Grain boundary sliding produces this effect.

6. The axial thermal expansions of $\mathrm{Eu}_{2} \mathrm{O}_{3}$ are similar to the axial thermal expansions of $\mathrm{Gd}_{2} \mathrm{O}_{3}$. Therefore, the susceptibility of $\mathrm{Eu}_{2} \mathrm{O}_{3}$ to grain coarsening during sintering controls the extent of microcracking.

7. A critical grain size of approximately $13 \mu \mathrm{m}$ is necessary to produce microcracking in monoclinic $\mathrm{Ta}_{2} \mathrm{O}_{5}-\mathrm{Eu}_{2} \mathrm{O}_{3}$ compositions. 


\section{LITERATURE CITED}

1. Ray, W. E. Fabrication of control rods for nuclear reactors, an AEC monograph. Rowman and Littlefield, New York, 1963,229 pp.

2. Gray, W. J. A preliminary survey of potential fast reactor control materials. Batelle Pacific Northwest Laboratories NBWL $* B * 297,1973$.

3. Curtis, C. W. and A. G. Tharp. Ceramic properties of europium oxide. J. Amer. Ceram. Soc., 42 [3], 151-156 (1959).

4. Suchome1, R. R. and 0. Hunter, Jr. Effects of temperature and microstructure on the elastic properties of selected $\mathrm{Eu}_{2} \mathrm{O}_{3}-\mathrm{HfO}_{2}$ compositions. J. Amer. Ceram. Soc., 59 [3-4], $149-152$ (1976).

5. Suchomel, R. R., R. S. Cook, M. F. Berard, and 0. Hunter, $\mathrm{Jr}$. $\mathrm{HfO}_{2}$ and $\mathrm{Ta}_{2} \mathrm{O}_{5}$ as grain growth inhibitors in $\mathrm{Eu}_{2} \mathrm{O}_{3}$. J. of Nuc1. Materials 61, 99-109 (1976).

6. Sawbridge, P. T. and N. A. Waterman. On the thermal expansion and crystallography of cubic (C) and monoclinic (B) forms of $\mathrm{Gd}_{2} \mathrm{O}_{3}$ in the temperature range 20 to $900^{\circ} \mathrm{C}$. J. Mat. Sci., 3 , 15-18 (1968).

7. Dole, S. L. and 0. Hunter, Jr. Elastic properties of some $\mathrm{Gd}_{2} \mathrm{O}_{3}-\mathrm{HfO}_{2}$ compositions. J. Nuc. Mat1. $\underline{59}, 207-14$ (1976).

8. Laz10, F. "Tesselated Stresses I-V". J. Iron Steel Inst. (London) 137-159 (1943); 150, 183-209 (1944); $\underline{152}, 207-228$ (1945); $164,5-26$ (1950).

9. Buessem, W. R. Internal ruptures and recombinations in anisotropic ceramic materials. Mechanical Properties of Engineering Ceramics, W. W. Kriegal and H. PaImour, III, eds., Interscience Publishers, New York, 1961.

10.: Likhachev, V. A. Microstructural strains due to thermal anisotropy. Soviet Physics-So1id State, 3 [6], 13301336,1961 .

11. Kuszyk, J. A. and R. C..Bradt. Influence of grain size on effects of thermal expansion anisotropy in $\mathrm{MgTi}_{2} \mathrm{O}_{5}$.
$\mathrm{J}$. Amer. Ceram. Soc., 56 [B], $420-423,1973$. 
12. Cleveland, J, J. and R. C. Bradt, Department of Materials Sciences, Pennsylvania State University, University Park, Pennsylvania, Priyate communication, December 22, 1976 .

13. Manning, W. R. Anomalous elastic behavior of polycrystalline $\mathrm{Nb}_{2} \mathrm{O}_{5}$, Unpublished $\mathrm{Ph} . \mathrm{D}$. thesis. Library, Iowa State University of Science and Technology, $1970,150 \mathrm{pp}$.

14. Haglund, J. A. and O. Hunter, Jr. Elastic properties of polycrystalline monoclinic $\mathrm{Gd}_{2} \mathrm{O}_{3}$. J. Amer. Ceram. Soc., 56 [6], 327-329 (1973).

15. Siebeneck, H. J., D. P. H. Hasselman, J. J. Cleveland, and R. C. Bradt. Effect of microcracking on the thermal diffusivity of $\mathrm{Fe}_{2} \mathrm{TiO}_{5}$. J. Amer. Ceram. Soc., 59 [5-6], 241-244 (1976).

16. Matsuo, Y. and H. Sasaki. Effect of grain size on microcracking in lead tilanate ceramics. J. Amer. Ceram. Soc., 49 [4], 229-230 (1966).

17. Bush, E. A. and F. A. Humme1. High temperature mechanical properties of ceramic materials: I. Magnesium dititanate. J. Amer. Ceram. Soc., 41 [6], 189-195 (1958).

18. Kirchner, H. P. and R. M. Gruver. Strength anisotropy grain size relations in ceramic oxides. J. Amer. Ceram. Soc., 53 [5], 232-236 (1970).

19. Charvat, F. R. and W. D. Kingery. Thermal conductivity XIII. J. Amer. Ceram. Soc., 40 [9], 306-15 (1957).

20. McPherson, $R$. Intercrystalline thermal stresses in polycrystalline rutile. J. Australian Ceram. Soc., $\underline{3}[2]$, 43-52. (1967).

21. Dole, S. L., O. Hunter, Jr. and C. J. Wooge. Department of Materials Science and Engineering, Iowa State University, Ames, Iowa. Elastic properties of monoclinic hafnium oxide at room temperature. Paper to be published.

22. Zener, C. Elasticity and anelasticity of metals. University of Chicago Press, Chicago, 1948.

23. Stacy, D. W. , J. K. Johnstone and D. R. Wilder. Axial thermal expansion of $\mathrm{HfO}_{2}$. J. Amer. Ceram. Soc., 55 [9], 482-3 (1972). 
24. Dole, S. L. Department of Materials Science and Engineering, Iowa State University, January 5, 1977, private communication.

25. Forster, F. A new method for the determination of the modulus of elasticity and damping. Zeit. Metallkunde, 29 [4], $109-115$ (1937).

26. Marlowe, M. O. Elasticity and kilocycle internal friction of $\mathrm{Y}_{2} \mathrm{O}_{3}$. Unpublished M.S. thesis. Library, Iowa State University of Sclence and Technology, Ames, Iowa, $1963,98 \mathrm{pp}$.

27. Pickett,.G. Equations for computing elastic constants from flexural and torsional resonant frequencies of vibrations and prisms and cylinders. ASTM Proc., 45, 846-865 (1945).

28. Hasselman, D. P. H. Tables for the computation of shear modulus and Young's modulus of elasticity from resonant frequencies of rectangular prisms. Carborundum Co., Niagara Falls, New York, 1961.

29. Razumov, V. I. and V. S. Postnikov. Apparatus for the measurement of the internal friction of the kilocycle range of frequencies. In Internal Friction in Metals and Alloys, Consultants Bureau, New York, 1967, pp. 207-210.

30. Wachtman, J. B., Jr. and W. E. Tefft. Effect of suspension position on apparent values of internal friction determined by Forster's method. Rev. Sci. Instrs., 29 $[6], 517-20(1958)$.

31. Ploetz, G. L., C. W. Krystyniak and.H. E. Dumas. Sintering characteristics of rare earth oxides. J. Amer. Ceram. Soc., 41 [12], 551-554 (1958).

32. Johnstone, J. K. The erbia-hafnia system. Unpublished $\mathrm{Ph}$.D. thesis, Library, Iowa State University of Science and Technology, Ames, Iowa, 1970.

33. Stacy, D. W. An x-ray diffraction study of the yttriahafnia system. Unpublished Ph.D. thesis. Library, Iowa State University of Science and Technology, Ames, Iowa, 1971 .

34. Campbe11, W. J. U.S. Bureau of Mines, Research Report No. 6115 (1962). 
35. Williams, Donald E. LCR 2 , A Fortran lattice constant refinement program USAEC Research and Development Report TID 4500 IS-105.2, October 1, 1964.

36. Fullman, R. L. Measurement of particle sizes in opaque bodies. Jour, Met, Trans. AIME, 1953, 447-452 (1953).

37. Manning, W. R., O, Hunter, Jr. and B. R. Powell, Jr. Elastic properties of polycrystalline yttrium oxide, dysprosium oxide, holmium oxide, and erbium oxide: room temperature measurements.' J, Amer. Ceram. Soc. 52 [8], 436-432 (1969).

38. Wachtman, J. B., Jr. Elastic deformation of ceramic and other refractory materials. National Bureau of Standards Special Publication 303,139-168; 1969 .

39. Hasselman, D. P. H. and R. M. Fulrath. Effect of small fraction of spherical porosity on elastic moduli of glass. J. Amer. Ceram. Soc., 47 [1], 52-53 (1964).

40. Wachtman, J. B., Jr. Mechanical properties of ceramics: an introductory survey. Amer. Ceram. Soc. Bul1., 46 $[8], 756-774$ (1967).

41. Blende11, John E., Robert L. Coble, and Richard J. Charles. On the relaxation of stresses arising from thermal expansion anisotropy during cooling polycrystalline aluminas. Presented at the Sixth International Symposium on Microstructures of Ceramic Materials, Berkeley, Calif., 1976.

42. Ke, T. A. Experimental evidence of viscous behavior of grain boundaries in metals. Physical Review 71, 533546,1947 .

43. Chang, R. Creep and elastic studies of $\mathrm{Al}_{2} \mathrm{O}_{3}$. U.S. Atomic Energy Commission Report NAA-SR-2770, North American Aviation, Inc., Downey, Calif., 1958.

44. Heuer, A. H., R. M. Cannon and N. J. Tighe. Plastic deformation in fine grain ceramics. In Ultrafine Grain Ceramics, J. Burke, N. Reed and V. Weiss, eds. University Press, 1970, pp. 339-363.

45. Hanna, R., and W. B. Cranda11. The Young's modulus and internal friction of polycrystalline MgO at room temperature. U.S. Atomic Energy Commission Report AROD-2891.1 Army Research Office, Durham, North Carolina, 1961. 
46. Snoek, J, L, Effect of smal1 quantities of carbon and nitrogen on the elastic and plastic properties of iron. Physica [8] 1941, pp. 711-733.

47. Ke, T. S. Internal friction and precipitation from the solid solution of nitrogen in tantalum. Physical Review [74] $1948, \mathrm{pp}$. $914 \div 916$.

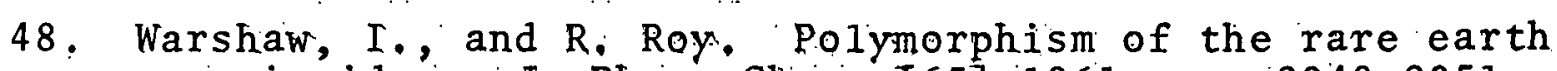
sesquioxides.'J. Phys. Chem. [65] 1961, pp. 2048-2051. 


\section{ACKNOWLEDGEMENTS}

The author would like to express his thanks to Dr. 0. Hunter for his constant help and guidance. Sincere appreciation is also expressed for the contributions that Dr. J. Smyth, Dr. D. Martin, and Dr. C. Burger made in writing this manuscript . 